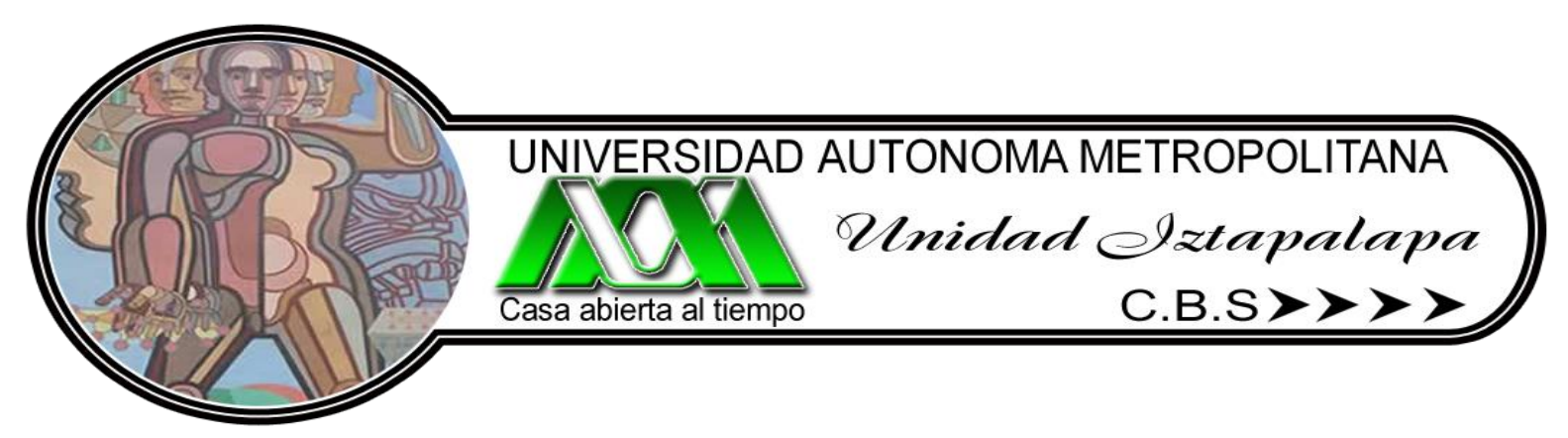

UNIVERSIDAD AUTÓNOMA METROPOLITANA

\author{
IZTAPALAPA
}

DIVISION DE CIENCIAS BIOLOGICAS Y DE LA SALUD

\title{
EFECTO DEL BENZOTRIAZOL SOBRE LA NITRIFICACION EN UN REACTOR DE LOTE SECUENCIADO (SBR).
}

\section{TESIS}

PARA OBTENER EL GRADO DE ESPECIALISTA EN BIOTECNOLOGIA

PRESENTA:

I.B.I. MARIA LYNET ACEVES ZAMORA

DIRECTORA DE TESIS:

DRA. ANNE-CLAIRE TEXIER 
Este trabajo fue realizado en el Laboratorio de Fisiología Microbiana (W-004) del Departamento de Biotecnología de la Universidad Autónoma Metropolitana, Unidad Iztapalapa; gracias al apoyo otorgado por el Consejo Divisional de la DCBS de la UAM-I. 
Iztapalapa, Ciudad de México a 28 de Agosto del 2017.

El jurado designado por la División de Ciencias Biológicas y de la Salud de la Unidad Iztapalapa.

\section{DIRECTORA DE TESIS}

Dra. ANNE-CLAIRE TEXIER

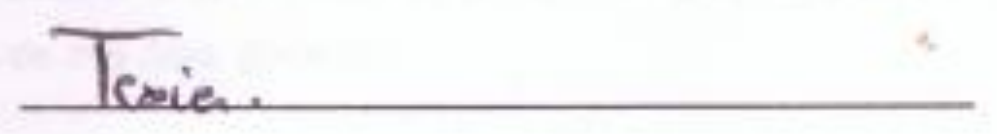

\section{LECTOR}

Dr. DIEGO IVAN BEJARANO ORTIZ

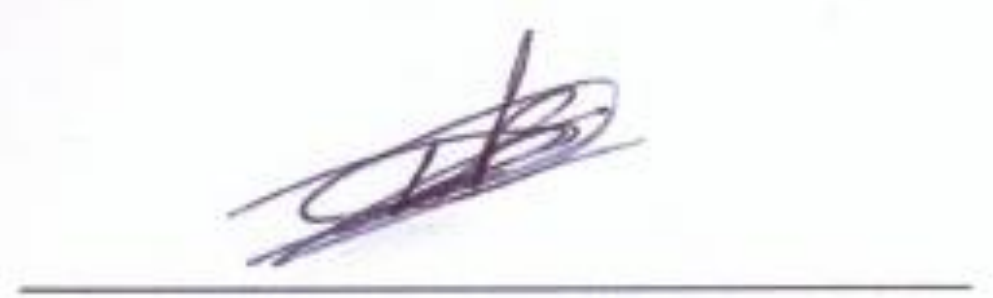




\section{AGRADECIMIENTOS}

Agradezco a la Dra. Anne-Claire Texier por la dirección, asesoría y revisión de este trabajo durante la Especialidad. ¡Gracias por su dedicación y tiempo invertido en mi formación!

Al Dr. Diego Iván Bejarano por su tiempo y dedicación al revisar mi trabajo, por sus comentarios y sugerencias ¡Gracias!

A la Dra. Flor de María Cuervo López por su colaboración a este trabajo, por sus sugerencias, disposición y críticas constructivas; que me ayudaron a la mejora de mi formación.

A todos los compañeros y amigos del W-004 Miguel, Yeni, Aarón, Cynthia, Juan y Eduardo, pero en especial a Daniel por sacarme una sonrisa con tus ocurrencias, por tu apoyo ¡Gracias!

A mis buenos amigos y malas influencias que me alentaron a continuar mi formación Paola, Karo, Toño, Benito y Dennis, por su apoyo y comprensión, muchas gracias.

A una persona que se volvió tan especial y con quien compartí gratos momento y aunque la vida nos separó, siempre será importante para mí.

A mi familia, mis padres y hermanos por su cariño, confianza y por su invaluable apoyo y paciencia, ¡Gracias! A mi tía Ana que más que eso es una amiga gracias por todo tu apoyo.

Y por último aunque no menos importante a Dios por haberme dado una familia maravillosa, por todas las bendiciones y abundancia en mi vida. Porque cada problema lo convertiste en bendición, cada dificultad en una lección, por darme una gran vida y por iluminar cada uno de mis días. ¡Gracias! 


\section{CONTENIDO}

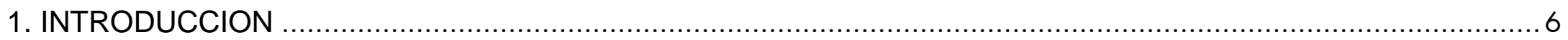

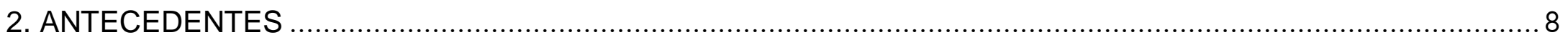

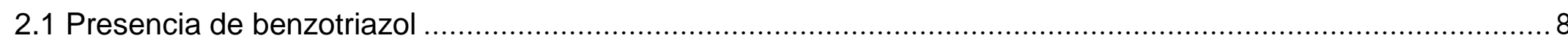

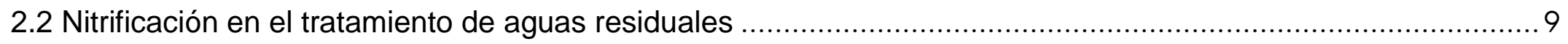

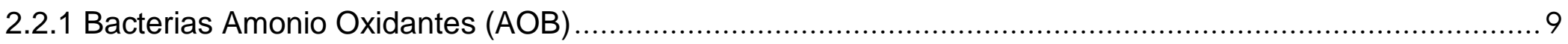

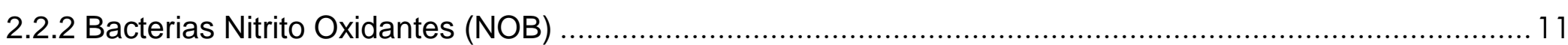

2.3 Efecto de compuestos aromáticos sobre la nitrificación ........................................................................... 11

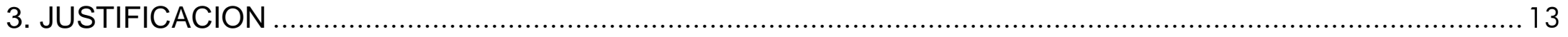

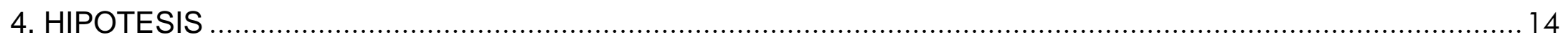

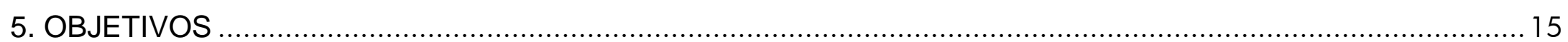

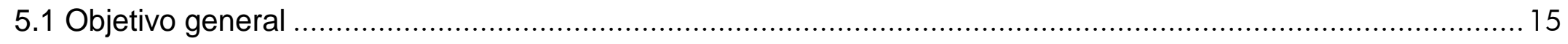

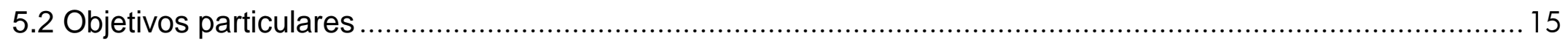

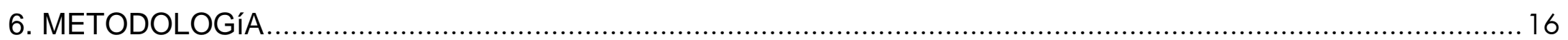

6.1 Inóculo

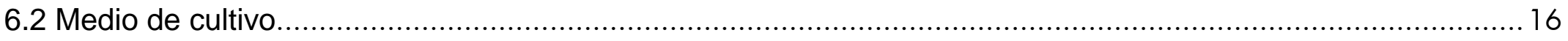

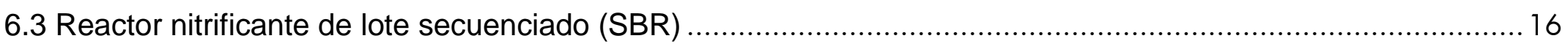

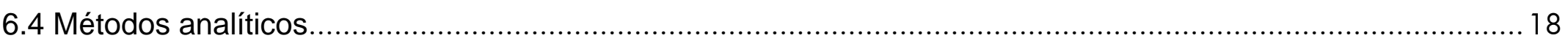

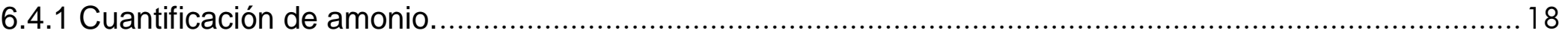

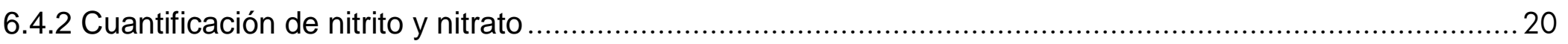

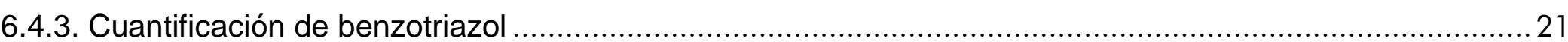

6.4.4 Cuantificación del crecimiento microbiano por Sólidos Suspendidos Volátiles (SSV) ...............................22

6.4.5 Cuantificación de proteína microbiana por método de Lowry modificado .................................................22

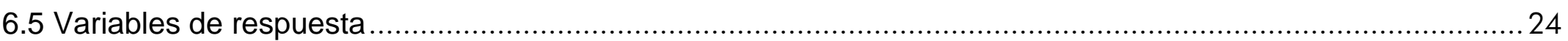

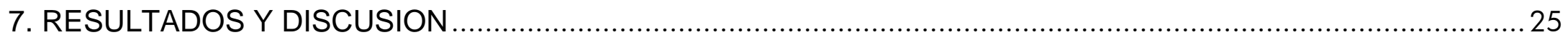


7.1 Nitrificación

7.2 Efecto del benzotriazol sobre la nitrificación. 28

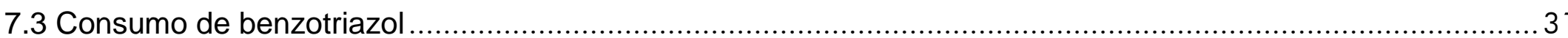

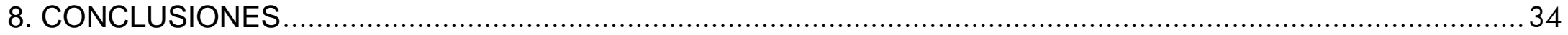

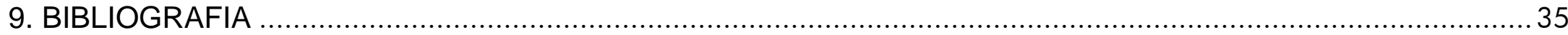




\section{INTRODUCCION}

El crecimiento poblacional a nivel mundial y el crecimiento industrial han incrementado los niveles de contaminación. Los contaminantes son generalmente introducidos directa o indirectamente en los mantos acuíferos por las actividades industriales, agrícolas o medidas irresponsables por parte de los municipios. Estos contaminantes son potencialmente dañinos para la salud humana y de otros organismos vivos aumentando el problema de la insuficiencia de los recursos de agua potable y contaminación de ecosistemas de agua dulce. Sin embargo, su impacto puede ser reducido mediante la preservación de los recursos hídricos y la mejora de las técnicas de gestión del agua.

Una clase emergente de contaminantes de interés se han agrupado dentro de los EOCs (Emerging Organic Compounds, por sus siglas en inglés). Dentro de este grupo, está el benzotriazol (BT) y sus derivados utilizados comercialmente. Son una clase de compuestos que consisten en un anillo de benceno fusionado a un anillo de cinco vértices que contiene tres átomos de nitrógeno. El benzotriazol tiene una serie de derivados tales como 5,6dimetilbenzotriazol (XTri), 5-metilbenzotriazol (5-MeBT), 4-metilbenzotriazol (4-MeBT) y 5-clorobenzotriazol (5-CBT).

Estos compuestos son inhibidores de la corrosión debido a su capacidad para formar una fina película protectora sobre superficies metálicas (Kadar y col., 2010; Kim y col., 2011). Por esta razón, los BTs se utilizan como agentes anticorrosión en los fluidos de corte (fluidos que se utilizan en la mayoría de las operaciones de mecanizado) y se pueden encontrar en muchos refrigerantes y lubricantes. Por lo tanto, se utilizan en los plásticos, componentes de automóviles, materiales de construcción, pinturas, cremas para la piel y champús (Zhang y col., 2011). Muchos productos de uso diario contienen compuestos de BT. Por tal motivo, contribuyen a la presencia de estos contaminantes en el medio ambiente especialmente en cuerpos de agua (Zwiener y Frimmel, 2004; Fawell y Ong, 2012).

Las propiedades químicas y físicas de los BTs pueden ser muy perjudiciales para el medio ambiente, especialmente provocando la contaminación del agua. Los BTs son de alta solubilidad en agua, altamente polares y no volátiles (Hart y col., 2004; Malhas y col., 2007; Liu y col., 2011). Muestran una fuerte resistencia a la oxidación en condiciones ambientales, se mantienen estables bajo irradiación UV moderada y su biodegradación es lenta (Wu y col., 1998). Estas propiedades hacen que puedan persistir en el medio ambiente por largos períodos de tiempo (Kim y col., 2011) y que sean difíciles de eliminar en plantas de tratamiento de aguas residuales convencionales (Weiss y Reemtsma, 2005; Reemtsma y col., 2006; Janna y col., 2011).

Si bien existe información sobre la incidencia, fuentes y concentraciones de BT y derivados, la información sobre el destino y el efecto de estos compuestos en el medio acuático es escasa (Jover y col., 2009; Matamoros y col., 2010). Los mecanismos de biodegradación y adsorción han sido reportados como los procesos más importantes en 
la eliminación de EOCs en aguas residuales. En medios acuáticos, el BT y 5-MeBT han sido reportados como muy resistentes a la biodegradación (Wu y col., 1998; Hem y col., 2000); sin embargo, la información relacionada a la biodegradación de los BTs es todavía escasa (Hollender y col., 2008).

Por otro lado, la contaminación del agua por compuestos nitrogenados ha afectado el ciclo natural del nitrógeno provocando acidificación y eutrofización de mantos acuíferos, afectando la capacidad de la flora y fauna para crecer y reproducirse. En algunos estudios, se ha investigado el consumo de agua contaminada con nitrito por el ser humano y se ha reportado que puede ocasionar cáncer en los consumidores al tener contacto el nitrito con la saliva y formar nitrosaminas (Ward y col., 2005).

El ciclo del nitrógeno lo conforman los siguientes procesos reductivos: fijación del nitrógeno, amonificación, reducción desasimilatoria del nitrato a amoniaco (RDNA), ANAMMOX y desnitrificación (Figura 1). La nitrificación es el único proceso oxidativo del ciclo. Los compuestos que están involucrados en el ciclo del nitrógeno pueden servir directamente como fuente de nitrógeno para diversos microorganismos, que, al transformarlos, nutren suelos y ambientes acuáticos para que organismos superiores obtengan nitrógeno para sintetizar nucleótidos y proteínas.

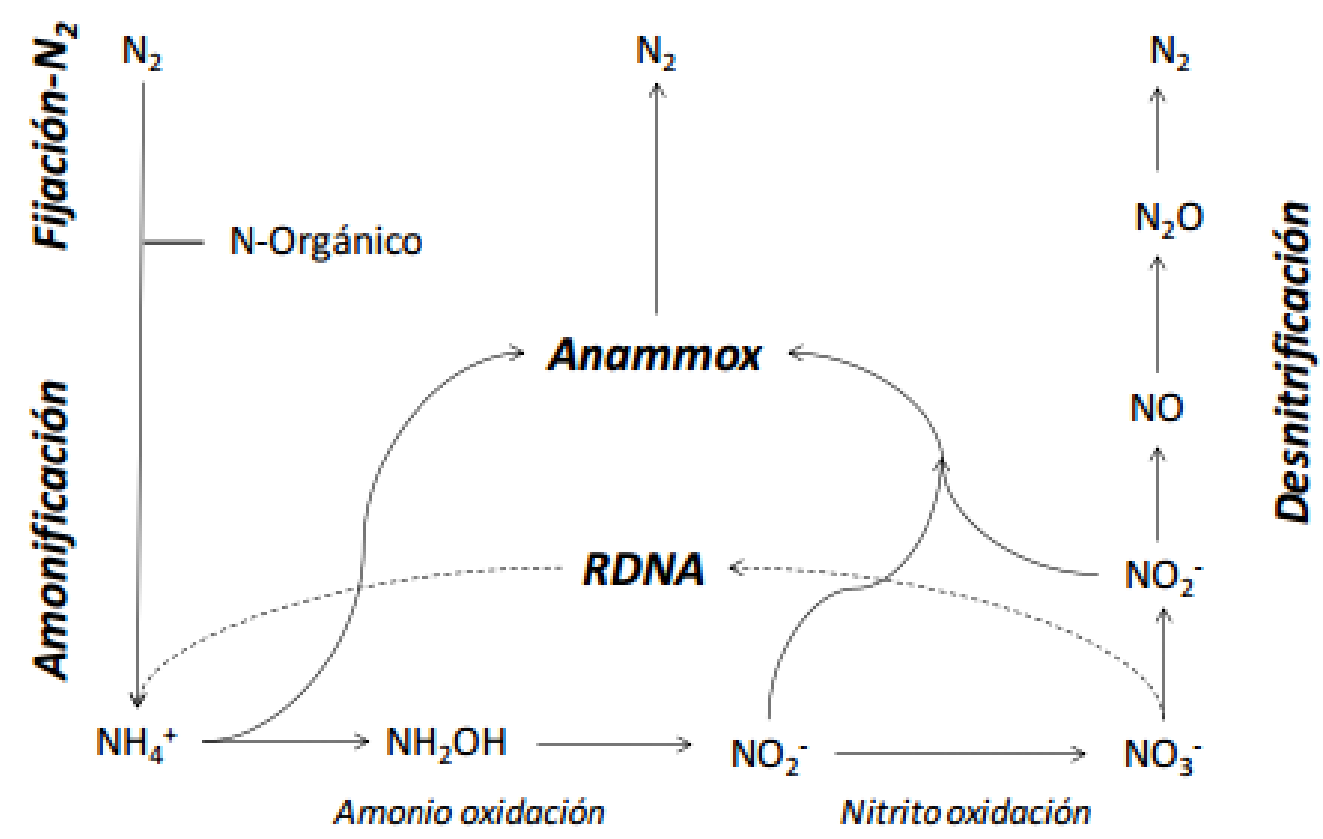

Nitrificación

Figura 1. Ciclo biogeoquímico del nitrógeno (Silva, 2011). 


\section{ANTECEDENTES}

\subsection{Presencia de benzotriazol}

La presencia de BT se ha detectado en ríos, agua subterránea, agua potable, aguas residuales, suelos e incluso en muestras humanas (Weiss y Reemtsma, 2005; Reemtsma y col., 2006; Janna y col., 2011; Asimakopoulos y col., 2013).

En estudios realizados en Estados Unidos y Suiza, se ha reportado que el BT es uno de los EOCs que se encuentran en mayores concentraciones en cuerpos de agua (Voutsa y col., 2006; McNeill y Cancilla, 2009). En el estudio suizo, se determinaron concentraciones de BT de hasta $100 \mathrm{mg} / \mathrm{L}$ en muestras de agua de río. La concentración media de BT en muestras procedentes de ríos europeos ha sido determinada de $0.5 \mathrm{mg} / \mathrm{L}$ (Reemtsma y col., 2006). En las muestras tomadas del río Glatt en Suiza, el 5-MeBT se encontró en concentraciones de hasta $6.3 \mathrm{mg} / \mathrm{L}$ (Giger y col., 2006). Cerca de allí, los resultados fueron similares, ya que se encontraron en el río Spree en Alemania y el lago Greifensee en Suiza concentraciones similares de BT (2.7 mg/L) y 5-MeBT (0.2 mg/L) (Giger y col., 2006; Weiss y col., 2006). En el estudio realizado por Kiss y Fries (2009), se encontró BT y 5-MeBT en el río Hegbach en Alemania, sin embargo, el río no recibe ningún efluente de agua residual para atribuir la presencia de estos compuestos, por lo tanto, su detección en los ríos se atribuyó a la red de alcantarillado de aguas residuales, la deposición atmosférica e incluso la extracción de agua subterránea que contiene el contaminante.

Otro estudio, realizado en Europa, evaluó 59 contaminantes persistentes EOCs que comprenden a productos farmacéuticos, antibióticos, pesticidas, ácidos perfluorados, hormonas, cafeína, Triclosan, BT y 5-MeBT (Loos y col., 2010). En este estudio, se recogieron 164 muestras de agua subterránea de 23 países, de las cuales se detectaron BT y 5-MeBT en aproximadamente el $53 \%$ de todas las muestras. Las concentraciones máximas de los compuestos fueron 1032 y $516 \mathrm{ng} / \mathrm{L}$, respectivamente. En otro estudio, ocho muestras con BT y cinco muestras con 5-MeBT tenían concentraciones que excedieron la norma de calidad de las aguas subterráneas en Europa (Loos y col., 2009).

Recientemente, se han detectado BTs en muestras de polvo de interior de los hogares rurales y urbanos en cuatro países: EUA, Japón, Corea y China (Wang y col., 2013). En este estudio, se recogieron 158 muestras para investigar la ocurrencia de los BTs y la exposición humana a ellos. Los resultados indicaron la presencia de benzotriazoles en todas las muestras. La fuente de BT y 5-MeBT en estas muestras podría ser el resultado de la deposición atmosférica (Kiss y Fries, 2009).

Estas concentraciones son significativamente superiores a las concentraciones que se cree que podrían ser tóxicas para los invertebrados, peces y las bacterias que dependen de estos cuerpos de agua para su supervivencia 
(Hartwell y col., 1995; Cornell y col., 2000). Varios autores han señalado la necesidad de realizar más investigación sobre los efectos tóxicos y crónicos del BT (Harris y col., 2007; Kadar y col., 2010; Janna y col., 2011). Además, Kiss y Fries (2012) indicaron que se debe tener cuidado en sacar conclusiones acerca de las evaluaciones de riesgo ambiental; debido a que los BTs se encuentran regularmente en el medio acuático a concentraciones inferiores de $\mu \mathrm{g} / \mathrm{L}$ reflejan su persistencia y mala eliminación durante los procesos de tratamiento de aguas residuales, hay pocos indicios de que los BTs suponen un riesgo para los ecosistemas acuáticos a los niveles de exposición actuales durante la mayor parte del año. Sin embargo, no se puede excluir ya que en invierno con un mayor uso de ADAFs (inhibidores de la corrosión) las concentraciones ambientales pueden exceder el nivel que se considera seguro para los organismos acuáticos.

\subsection{Nitrificación en el tratamiento de aguas residuales}

En el tratamiento de aguas residuales, la nitrificación es la primera etapa en varios sistemas biológicos para la eliminación de nitrógeno. La nitrificación es un proceso respiratorio aerobio que implica la oxidación quimiolitoautotrófica del amonio a nitrato, llevada a cabo en dos etapas y por dos grupos de bacterias Gram negativas filogenéticamente no relacionadas (Bernet y Spérandio, 2009). En la primera etapa, el amonio es oxidado a nitrito (nitritación) por las bacterias amonio oxidantes (AOB por sus siglas en inglés). Posteriormente, el nitrito es oxidado a nitrato (nitratación) por las bacterias nitrito oxidantes (NOB, por sus siglas en inglés) (Prosser, 1989; Bock y col., 1991). En cada etapa, se utiliza amonio o nitrito como fuente de energía, oxígeno molecular como aceptor final de electrones y $\mathrm{CO}_{2}$ como fuente de carbono.

\subsubsection{Bacterias Amonio Oxidantes (AOB)}

Las bacterias amonio oxidantes han sido aisladas de suelos, ríos, lagos y océanos. Presentan diversos tipos de morfologías como espirales, cocos y bacilos. Se ha observado un mayor crecimiento en intervalos de temperatura de 25 a $30^{\circ} \mathrm{C} \mathrm{y} \mathrm{pH}$ entre 7.5 y 8.0 (Bock y col., 1991). Estas se han dividido de acuerdo a sus características fenotípicas en cinco géneros: Nitrosomonas, Nitrosolobus, Nitrosovibrio, Nitrosococcus y Nitrosospira (Watson y col., 1989).

La amonio oxidación es iniciada por la enzima amonio monooxigenasa (AMO), la cual oxida el amonio a hidroxilamina $\left(\mathrm{NH}_{2} \mathrm{OH}\right)$ mediante el consumo de oxígeno molecular y dos electrones (Figura 2). Posteriormente, la enzima hidroxilamina oxidoreductasa (HAO) oxida la hidroxilamina a nitrito. 


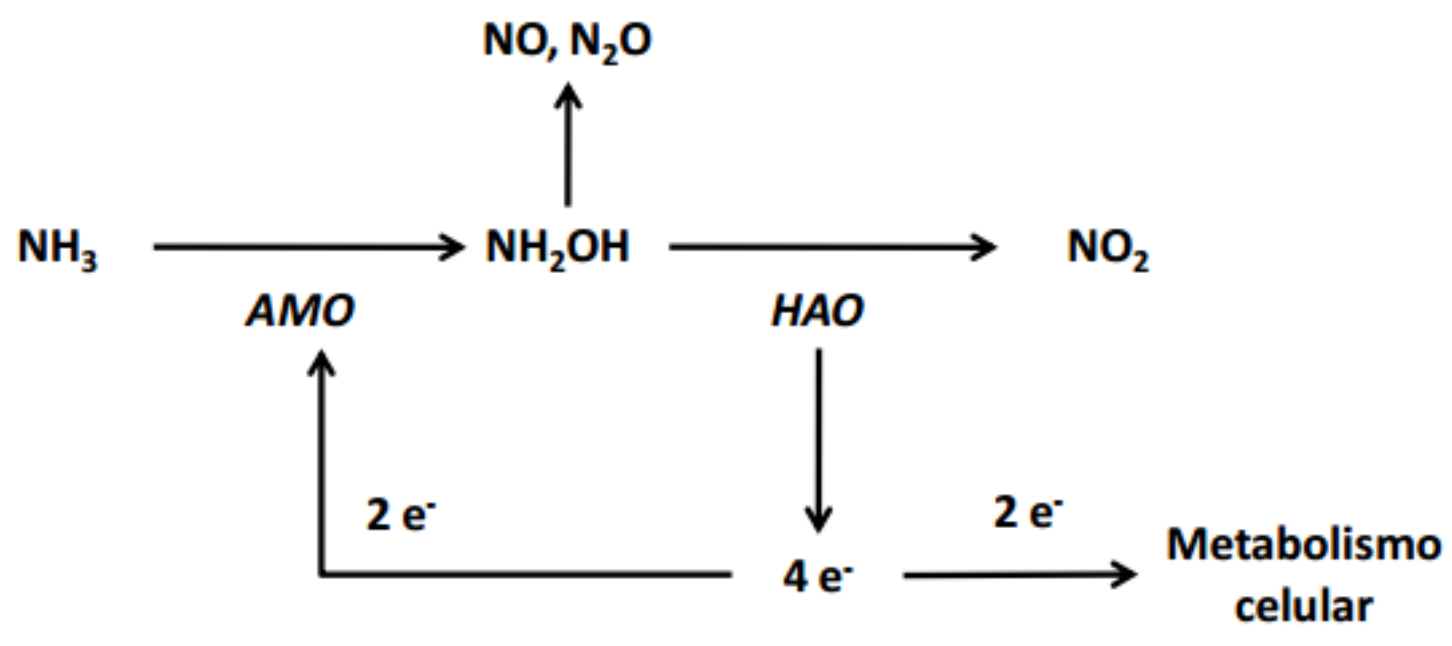

Figura 2. Vía amonio oxidante en las AOB (Silva, 2011).

De esta serie de reacciones se producen cuatro electrones, de los cuales, dos se reciclan hacia a la AMO para su actividad y únicamente dos electrones entran a la cadena respiratoria para la generación de energía (Kowalchuk y Stephen, 2001). El amonio es oxidado de acuerdo con las siguientes ecuaciones parciales (1) y (2), resultando en la ecuación global (3) para la etapa amonio oxidante (Silva, 2011).

$\begin{array}{lll}\text { Ecuación 1 } & \mathrm{NH}_{4}^{+}+\mathrm{O}_{2} \mathrm{O}_{2} \longrightarrow \mathrm{NH}_{2} \mathrm{OH}+\mathrm{H}^{+} & \Delta \mathrm{G}^{\circ \prime}=-8.2 \mathrm{~kJ} \mathrm{~mol}^{-1} \\ \text { Ecuación 2 } & \mathrm{NH}_{2} \mathrm{OH}+\mathrm{O}_{2} \longrightarrow \mathrm{NO}_{2}^{-}+\mathrm{H}^{+}+\mathrm{H}_{2} \mathrm{O} & \Delta \mathrm{G}^{\circ \prime}=-266.5 \mathrm{~kJ} \mathrm{~mol}^{-1} \\ \text { Ecuación 3 } & \mathrm{NH}_{4}^{+}+1.5 \mathrm{O}_{2} \longrightarrow \mathrm{NO}_{2}^{-}+2 \mathrm{H}^{+}+\mathrm{H}_{2} \mathrm{O} & \Delta \mathrm{G}^{\circ \prime}=-274.7 \mathrm{~kJ} \mathrm{~mol}^{-1}\end{array}$

La ecuación (4) representa el proceso anabólico en la ruta amonio oxidante, tomando en cuenta la fórmula empírica de la célula (Silva, 2011).

Ecuación $4 \quad 55 \mathrm{NH}_{4}^{+}+76 \mathrm{O}_{2}+109 \mathrm{HCO}_{3}{ }^{-} \longrightarrow \mathrm{C}_{5} \mathrm{H}_{7} \mathrm{O}_{2} \mathrm{~N}+54 \mathrm{NO}_{2}{ }^{-}+56 \mathrm{H}_{2} \mathrm{O}+104 \mathrm{H}_{2} \mathrm{CO}_{3}$ 


\subsubsection{Bacterias Nitrito Oxidantes (NOB)}

Las bacterias nitrito oxidantes se han dividido en cuatro géneros reconocidos como: Nitrobacter, Nitrococcus, Nitrospira y Nitrospina. Están catalogadas como quimiolitoautótrofas, ya que utilizan el nitrito como fuente de energía y carbono inorgánico para su crecimiento. Sin embargo, no todas las NOB son quimioautótrofas obligadas. De hecho, algunas cepas de Nitrobacter pueden crecer heterotróficamente (donde la energía y el carbono son obtenidos de una fuente orgánica de carbono) o mixotróficamente (nitrito como fuente de energía y acetato o piruvato como fuente de carbono) (Smith y Hoare, 1968; Steinmüller y Bock, 1977; Watson y col., 1989). El crecimiento de las NOB puede ocurrir desde un pH de 6.5 a 8.6 y a temperaturas entre los 5 a $37^{\circ} \mathrm{C}$ (Watson y col., 1989). Las NOB presentan morfologías como cocos y bacilos y pueden encontrarse en suelos, rocas y ríos (Bock y col., 1991).

La oxidación de nitrito a nitrato es catalizada por acción de un complejo enzimático llamado nitrito óxido reductasa (NOR) que se encuentra en la superficie de la membrana citoplasmática (Bock y col., 1991).

La reacción de nitrito oxidación se muestra en la ecuación 5.
Ecuación 5
$\mathrm{NO}_{2}^{-}+0.5 \mathrm{O}_{2} \longrightarrow \mathrm{NO}_{3}{ }^{-}$
$\Delta \mathrm{G}^{\circ}=-74.1 \mathrm{~kJ} \mathrm{~mol}^{-1}$

A continuación, se muestra la oxidación asimilativa del nitrito por las NOB (Bernet y Spérandio, 2009).

Ecuación 6

$$
400 \mathrm{NO}_{2}^{-}+\mathrm{NH}_{4}^{+}+195 \mathrm{O}_{2}+4 \mathrm{H}_{2} \mathrm{CO}_{3}+\mathrm{HCO}_{3}^{-} \longrightarrow \mathrm{C}_{5} \mathrm{H}_{7} \mathrm{O}_{2} \mathrm{~N}+400 \mathrm{NO}_{3}^{-}+3 \mathrm{H}_{2} \mathrm{O}
$$

\subsection{Efecto de compuestos aromáticos sobre la nitrificación}

Se sabe que hay un efecto negativo de la materia orgánica en la nitrificación, y que la estabilidad de los sistemas nitrificantes en el tratamiento de aguas residuales puede ser alterada por la presencia de compuestos orgánicos tóxicos e inhibitorios (Schweighofer y col., 1996). Así pues, en el tratamiento de aguas residuales por nitrificación, el control de la materia orgánica es de suma importancia.

Por otro lado, cultivos nitrificantes han demostrado ser capaces de oxidar una amplia variedad de compuestos orgánicos que van desde compuestos simples como los ácidos grasos volátiles, hasta compuestos aromáticos, fenólicos y halogenados. 
En el estudio de Nevalainen y col. (1993), se encontró que el 2,4,6-triclorofenol en lodos activados con actividad nitrificante, no tuvo efecto sobre la conversión de $\mathrm{NH}_{4}{ }^{+}$a $\mathrm{NO}_{3}{ }^{-}$y se obtuvo un consumo del $100 \%$ del compuesto aromático. En el 2004 se presentó un estudio con formaldehido utilizando lodos activados, obteniéndose una eficiencia del $100 \%$ del compuesto orgánico y una alta producción de $\mathrm{NO}_{2}{ }^{-}$y $\mathrm{NO}_{3}{ }^{-}$(Eiroa y col. 2004).

Al agregar p-cresol en consorcios nitrificantes, se observó un efecto inhibitorio en la nitrificación, disminuyendo las velocidades específicas de oxidación de amonio y de nitrito (Silva, 2011). Los lodos presentaron una capacidad de consumo del $100 \%$ de la materia orgánica a la que estuvo expuesta, obteniéndose $\mathrm{CO}_{2}$ como producto final mayoritario (Silva y col., 2009). A pesar del efecto inhibitorio del p-cresol sobre la nitrificación, ésta pudo llevarse a cabo eficientemente y totalmente en un reactor de lotes secuenciados (SBR) con altos valores de eficiencia y rendimiento de nitrato (Silva y col., 2014).

El 2-clorofenol en un consorcio nitrificante provocó una disminución de $90 \%$ en la eficiencia de consumo de amonio y $95 \%$ en la velocidad específica de oxidación de amonio, con una eficiencia de consumo del compuesto fenólico del 100\% (Martínez-Hernández y col. 2011).

Esta capacidad de lodos nitrificantes en oxidar compuestos aromáticos tiene gran relevancia para los sistemas de tratamiento biológico de eliminación del nitrógeno amoniacal, donde hay presencia de compuestos orgánicos, ya que abre la posibilidad de la eliminación simultánea de contaminantes. 


\section{JUSTIFICACION}

La escasez de agua en las grandes ciudades, obliga a los gobiernos a implementar tecnologías para limpiar el agua contaminada para su posible reutilización o descarga en cuerpos hídricos. Si las aguas residuales de origen doméstico e industrial no son tratadas, pueden ocasionar problemas graves al ambiente y al ser humano.

Se ha demostrado que la eliminación de muchos microcontaminantes (aún no regulados, llamados compuestos orgánicos emergentes (EOCs por sus siglas en inglés)) es incompleta en las plantas de tratamiento de aguas. Es importante contar entonces con tratamientos que puedan eliminar simultáneamente nitrógeno amoniacal y compuestos emergentes. El tratamiento biológico por nitrificación-desnitrificación es una opción viable para eliminar estos compuestos del agua debido a su bajo costo y alta eficiencia. La nitrificación es considerada como el paso limitante de este sistema, por lo tanto, surge la necesidad de aumentar el conocimiento sobre el comportamiento de lodos nitrificantes en presencia de compuestos emergentes. El benzotriazol es uno de los EOCs detectado en efluentes de plantas de tratamiento de aguas a mayores concentraciones y mayor frecuencia. Se desconoce su efecto sobre la eliminación de amonio de las aguas por nitrificación, así como el papel que puedan tener los lodos nitrificantes en su eliminación. Por todo lo anterior, es necesario realizar una mayor investigación en este tema. 


\section{HIPOTESIS}

La nitrificación podrá llevarse a cabo de manera completa, con alta eficiencia de eliminación de amonio y formación de nitrato, aun en presencia de un compuesto inhibitorio como el benzotriazol. 


\section{OBJETIVOS}

\subsection{Objetivo general}

- Evaluar la actividad respiratoria nitrificante de un lodo expuesto a benzotriazol.

\subsection{Objetivos particulares}

- En un reactor de lote secuenciado (SBR), evaluar el efecto de benzotriazol sobre la respiración de un lodo con actividad nitrificante a través de variables de respuesta como eficiencia de consumo de amonio y rendimientos en nitrito y nitrato.

- Evaluar el efecto inhibitorio del benzotriazol sobre la nitrificación a través de las velocidades específicas de consumo de amonio y nitrito oxidación durante el paso de los ciclos de operación del SBR.

- Evaluar la capacidad de consumo del benzotriazol por el lodo nitrificante durante los ciclos de operación. 


\section{METODOLOGÍA}

\subsection{Inóculo}

Se utilizó un consorcio nitrificante proveniente de un reactor de lotes secuenciados que estuvo alimentado con amonio y una mezcla de compuestos fenólicos y sulfuro en el laboratorio de Fisiología Microbiana de la UAMIztapalapa (Suárez García, 2016).

\subsection{Medio de cultivo}

El reactor de lote secuenciado se alimentó con un medio de cultivo definido para el proceso nitrificante con una concentración inicial de $149.0 \pm 0.4 \mathrm{mg} \mathrm{N}^{-N_{4}}{ }_{4}{ }^{+} / \mathrm{L}$ y $380 \pm 0.8 \mathrm{mg} \mathrm{C}-\mathrm{NaHCO}_{3} / \mathrm{L}$, dando una relación $\mathrm{C} / \mathrm{N}$ de 2.5 (Tabla 1). El medio resulta de la mezcla de un medio como fuente de $\mathrm{N}$ y otro como fuente de $\mathrm{C}$, los cuales son alimentados por separado para evitar la posible precipitación de sales. La concentración inicial de benzotriazol fue de $5 \mathrm{mg} / \mathrm{L}$.

Tabla 1. Composición del medio para el reactor nitrificante.

\begin{tabular}{cc|cc}
\hline $\begin{array}{c}\text { Fuente de nitrógeno } \\
\text { Composición de sales }\end{array}$ & $\begin{array}{c}\text { Concentración } \\
(\mathrm{g} / \mathrm{L})\end{array}$ & $\begin{array}{c}\text { Fuente de carbono } \\
\text { Composición de sales }\end{array}$ & $\begin{array}{c}\text { Concentración } \\
(\mathrm{g} / \mathrm{L})\end{array}$ \\
\hline$\left(\mathrm{NH}_{4}\right)_{2} \mathrm{SO}_{4}$ & 0.19 & $\mathrm{NaHCO}_{3}$ & 1.75 \\
$\mathrm{NH}_{4} \mathrm{Cl}$ & 0.24 & $\mathrm{CaCl}_{2}$ & \\
$\mathrm{KH}_{2} \mathrm{PO}_{4}$ & 0.28 & & \\
$\mathrm{MgSO}_{4}$ & 0.20 & & \\
$\mathrm{NaCl}$ & 0.20 & & \\
\hline
\end{tabular}

\subsection{Reactor nitrificante de lote secuenciado (SBR)}

Se inoculó en un reactor con una capacidad nominal de 3 L (Applikon, mod. P100) y un volumen de operación de 2 L. Se alimentó del medio de cultivo mediante una bomba peristáltica (Master-Flex, Cole-Parmer, cabezal 7518-00). La operación del reactor contó con una aireación constante suministrada por bombas de aire (hagen, mod. Elite 800), una agitación de $250 \mathrm{rpm}$, una temperatura de $25 \pm 0.5^{\circ} \mathrm{C}$ y un valor promedio de $\mathrm{pH}$ de $8.2 \pm 0.2$. Se utilizó bicarbonato de sodio como amortiguador. El sobrenadante del reactor se bombeó por medio de una bomba peristáltica (Master-Flex, Cole Palmer, 7524-40). 
La alimentación, agitación, aireación, así como el drenado fueron controlados por temporizadores digitales (TEMP08E) que permiten el encendido y apagado de las bombas de acuerdo al tiempo programado.

Los ciclos de operación del SBR tuvieron una duración de 24 horas y fueron divididos en 4 etapas (Figura 3) (Texier y Gómez, 2004): alimentación (5 minutos), reacción biológica (23 horas), sedimentación (45 minutos) y drenado (10 minutos).

Se tomaron muestras al inicio y final de cada lote para medir el consumo de amonio y la formación de nitrito y nitrato; así como también, muestras para medir el consumo del benzotriazol, la formación de biomasa (proteína microbiana y SSV), pH y oxígeno disuelto.

Se realizaron cinéticas de consumo de amonio, benzotriazol y formación de nitrito y nitrato para evaluar el efecto del BT sobre las velocidades del proceso nitrificante.

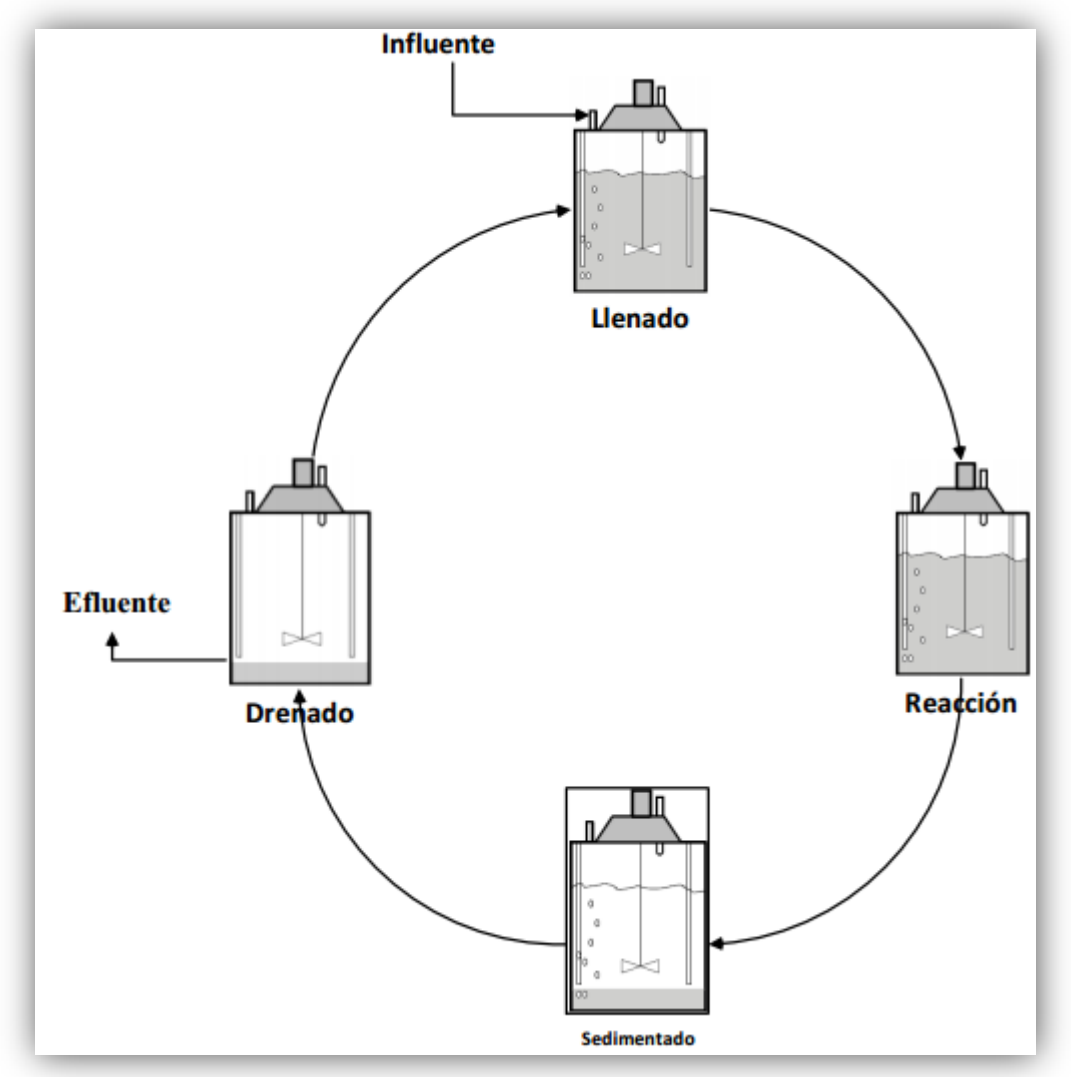

Figura 3. Etapas del ciclo de operación de un Reactor SBR (Salas Cortes, 2014). 


\subsection{Métodos analíticos}

Se realizaron al menos tres curvas de calibración para cada técnica analítica utilizada (Tabla 2).

Tabla 2. Coeficiente de variación en el valor de la pendiente y coeficiente de determinación de los métodos analíticos.

\begin{tabular}{ccc} 
Análisis & $\begin{array}{c}\text { Coeficiente de variación } \\
(\mathbf{C V}, \%)\end{array}$ & $\begin{array}{c}\text { Coeficiente de determinación } \\
\left(\mathbf{R}^{\mathbf{2}}\right)\end{array}$ \\
\hline Benzotriazol (HPLC) & 0.8 & $0.988 \pm 0.01$ \\
\hline Amonio (Electrodo selectivo) & 1.5 & $0.989 \pm 0.06$ \\
\hline Nitrito (HPLC) & 1.2 & $0.988 \pm 0.01$ \\
\hline Nitrato (HPLC) & 1.7 & $0.987 \pm 0.02$ \\
\hline Proteína microbiana (método de Lowry) & 1.1 & $0.988 \pm 0.006$ \\
\hline
\end{tabular}

Todos los métodos presentaron un CV menor al 1.7\%, lo cual indicó una aceptable reproducibilidad, mientras que los $\mathrm{R}^{2}$ fueron mayores que 0.98 , demostrando una respuesta lineal de los métodos.

\subsubsection{Cuantificación de amonio.}

Se utilizó un electrodo de ion selectivo para cuantificar el amonio disuelto en solución acuosa mediante su conversión a amoniaco. El principio del método se basa en desplazar el equilibrio del par $\mathrm{NH}_{4}{ }^{+} / \mathrm{NH}_{3}$ en solución acuosa mediante la alcalinización de las muestras. El electrodo selectivo cuenta con una membrana permeable al amoniaco. Por lo cual fue necesario alcalinizar todas las muestras con $\mathrm{NaOH} 10 \mathrm{~N}$, bajo agitación constante y temperatura ambiente. El electrodo estuvo acoplado a un potenciómetro portátil que permitió la lectura del potencial $(\mathrm{mV})$ cuando fue estable (aproximadamente $3 \mathrm{~min}$ después de adicionar el $\mathrm{NaOH}$ ). El valor del potencial es proporcional al logaritmo de la concentración, cuyo valor puede ser calculado directamente de la ecuación de la recta (Figura 4). Las ecuaciones (7) y (8) fueron utilizadas para calcular la concentración de amonio en las muestras. 
Ecuación 7

$$
\text { Potencial }=m\left(\text { logaritmo }\left(\left[\mathrm{NH}_{4}^{+}\right]\right)\right)+b
$$

Ecuación 8

$$
\left[\mathrm{NH}_{4}^{+}\right]=\operatorname{antilog}\left(\frac{\text { Potencial }-b}{m}\right)
$$

Dónde: $m$ es la pendiente; $b$ es la ordenada al origen

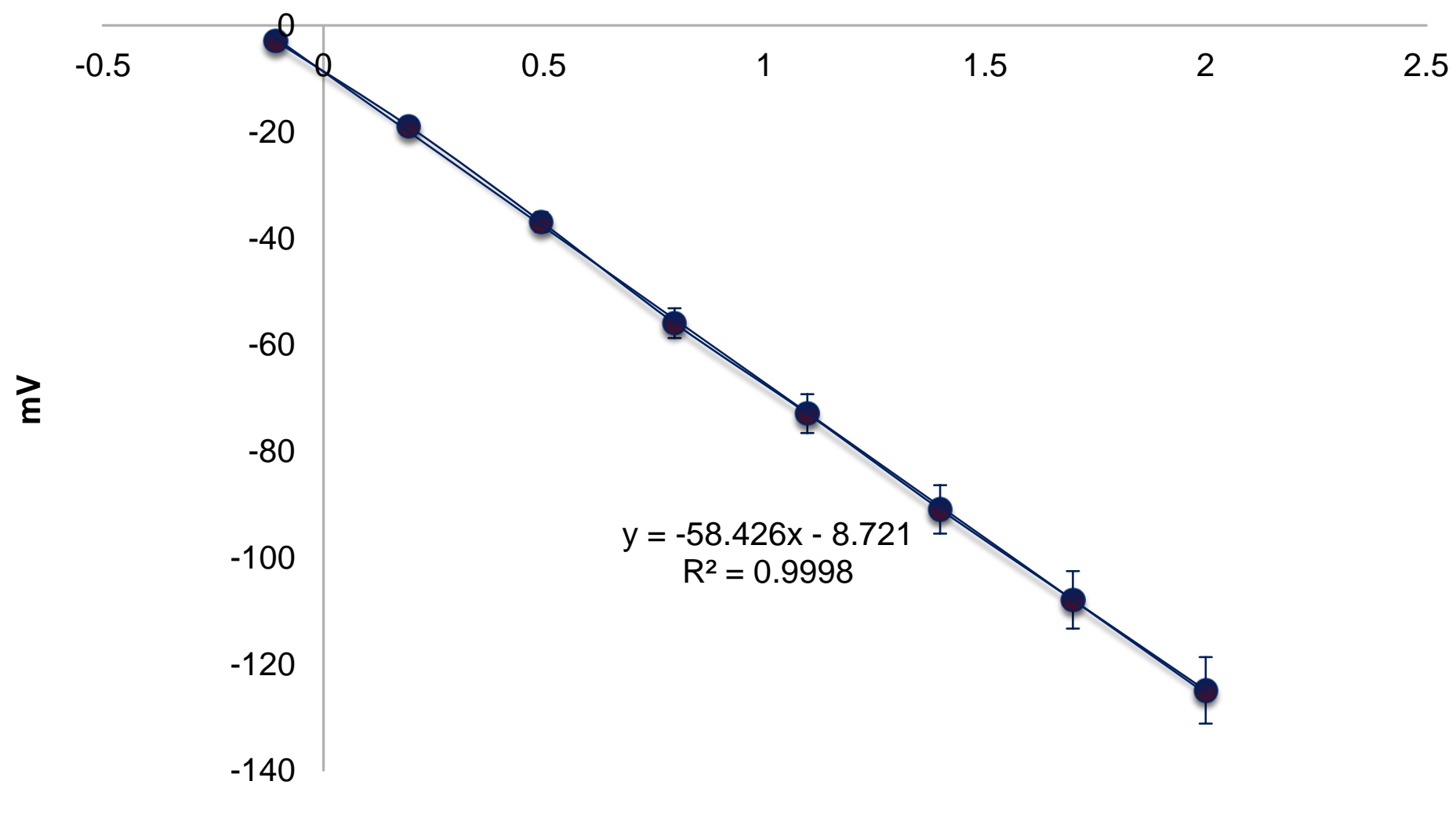

\section{$\log [\mathrm{NH} 4]$}

Figura 4. Curva de calibración para la cuantificación de amonio. 


\subsubsection{Cuantificación de nitrito y nitrato}

Para la cuantificación de nitrato y nitrito se utilizó cromatografía de líquidos (HPLC). En la cromatografía de intercambio iónico, la fase estacionaria es una resina de intercambio y la separación está gobernada por la fuerza de las interacciones entre los iones y los sitios de intercambio de la resina. Se utilizó una columna de intercambio iónico a una longitud de onda de $214 \mathrm{~nm}$. La fase móvil estuvo compuesta de: $20 \mathrm{~mL}$ de $n$-butanol, $120 \mathrm{~mL}$ de acetonitrilo y $20 \mathrm{~mL}$ de solución borato-gluconato, llevados con agua desionizada a un volumen final de $1 \mathrm{~L}$. El flujo fue de 1.5 $\mathrm{mL} / \mathrm{min}$. Las muestras fueron filtradas (membrana, $0.2 \mu \mathrm{m}$ ) y colocadas en viales para su análisis. La Figura 5 muestra un ejemplo de las curvas de calibración establecidas.

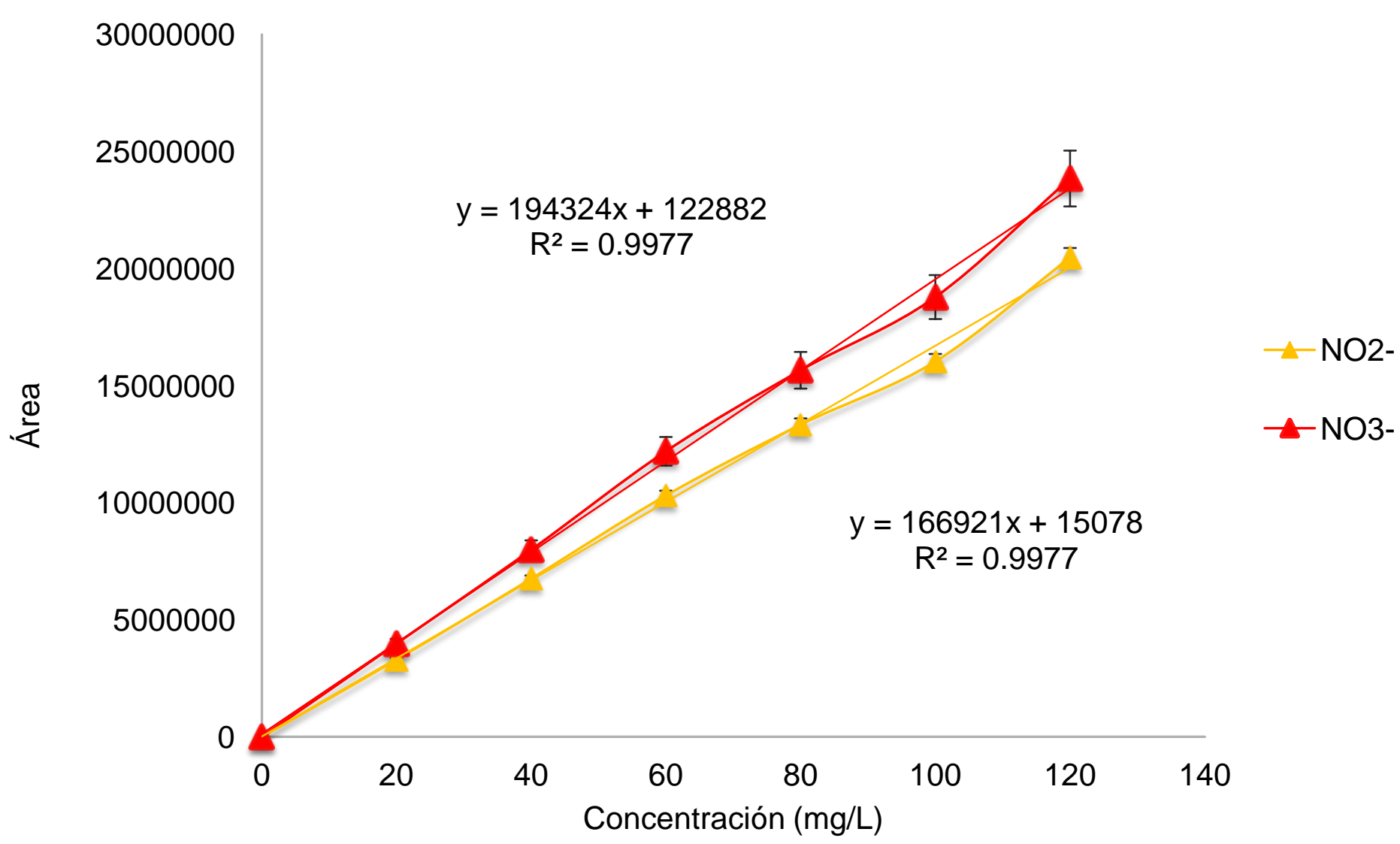

Figura 5. Curva de calibración para la cuantificación de nitrito y nitrato por HPLC. 


\subsubsection{Cuantificación de benzotriazol}

Para la cuantificación del benzotriazol se utilizó cromatografía de líquidos (HPLC). La separación de los compuestos aromáticos está determinada por la fuerza de las interacciones con la fase estacionaria que forma parte de la columna de separación, así como la composición de la fase móvil. Se utilizó un cromatógrafo de líquidos empleando una columna C18. El equipo cuenta con un detector UV/VIS y se fijó la longitud de onda a $274 \mathrm{~nm}$. La fase móvil fue una mezcla de metanol y agua $(60: 40 \mathrm{v} / \mathrm{v})$ y se trabajó a un flujo de $1.5 \mathrm{~mL} / \mathrm{min}$. El tiempo de corrida fue de $6 \mathrm{~min}$. Las muestras fueron filtradas por una membrana de $0.2 \mu \mathrm{m}$ y colocadas en viales para su análisis. La Figura 6 muestra un ejemplo de las curvas de calibración para la cuantificación de benzotriazol.

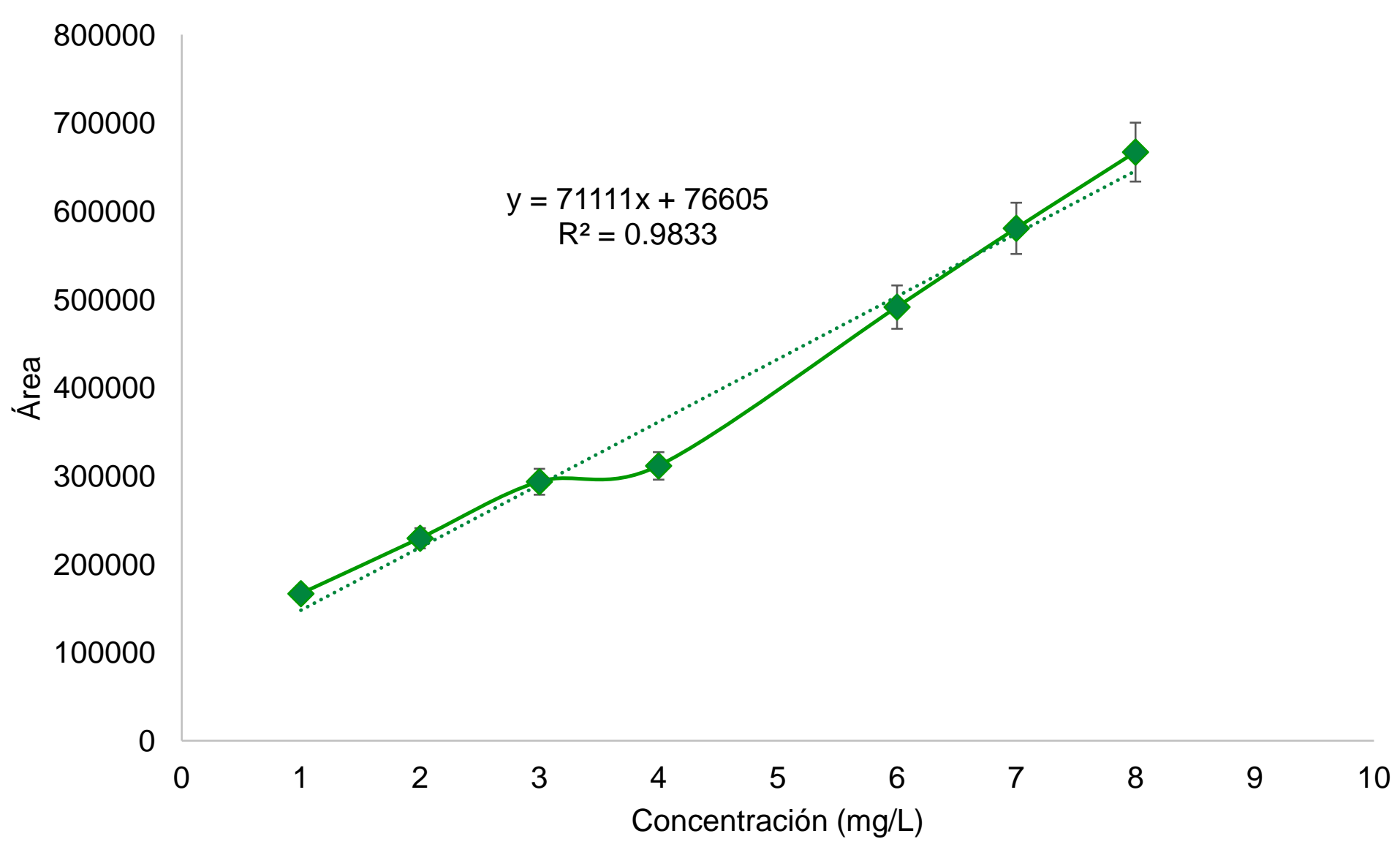

Figura 6. Curva de calibración para la cuantificación de benzotriazol por HPLC. 


\subsubsection{Cuantificación del crecimiento microbiano por Sólidos Suspendidos Volátiles (SSV)}

Los SSV son aquellos que se volatilizan a una temperatura de $520^{\circ} \mathrm{C}$. Si los sólidos totales se someten a combustión bajo una temperatura de $520^{\circ} \mathrm{C}$ durante un tiempo determinado, la materia orgánica se convierte a $\mathrm{CO}_{2}$ y $\mathrm{H}_{2} \mathrm{O}$. Esta pérdida de peso se interpreta en términos de materia orgánica o volátil. Se coloca una cápsula de porcelana por duplicado limpia en una mufla a ignición a $520^{\circ} \mathrm{C}$ por 1 hora. Se enfría y guarda la cápsula en un desecador hasta ser utilizada. Se pesa inmediatamente antes de usar; se agregan $10 \mathrm{~mL}$ de la muestra y se deja a $103-105^{\circ} \mathrm{C}$ en una mufla durante 1 día. Se deja enfriar la capsula en el desecador y se pesa nuevamente; después se somete a ignición el residuo obtenido hasta obtener peso constante en una mufla a $520^{\circ} \mathrm{C}$ durante $60 \mathrm{~min}$. Se deja enfriar la cápsula parcialmente en el aire hasta que la mayor parte del calor se haya disipado y se deja en el desecador para enfriamiento total. El contenido de sólidos suspendidos volátiles se calcula de la siguiente relación, en la ecuación (9):

\section{Ecuación 9}

$$
\text { SSV en } m g L^{-1}=\frac{(A-B) * 1000000}{V}
$$

Donde:

$\mathrm{A}=$ Peso del residuo + capsula antes de la ignición (g)

$\mathrm{B}=$ Peso del residuo + capsula de evaporación después de la ignición $(\mathrm{g})$

$\mathrm{V}=$ Volumen tomado de la muestra $(\mathrm{mL})$

\subsubsection{Cuantificación de proteína microbiana por método de Lowry modificado}

El método colorimétrico de Lowry modificado (Lowry y col., 1951; Martínez y col., 2000) fue utilizado para determinar la concentración de proteína microbiana en el reactor de lotes secuenciados. El método se basa en la reacción para formar un complejo Cu-proteína y la posterior reducción de este complejo por el reactivo de Folin-Ciocalteau, donde se obtiene un color azul en un ambiente alcalino ( $\mathrm{pH}$ de 10). El reactivo de Folin-Ciocalteau (Hycel) está formado por molibdato, fosfato y tungstato de sodio y produce un máximo de absorción a $750 \mathrm{~nm}$. Esta técnica requiere de proteínas que contengan péptidos con grupos fenólicos que puedan enlazarse con el $\mathrm{Cu}^{2+}$. Para cada serie de muestras analizadas, se preparó una curva de calibración de albúmina (Sigma, 96-99\%) de 0 a 300 mg/L. Las 
muestras y los estándares recibieron el mismo tratamiento. Se tomó $1 \mathrm{~mL}$ de muestra y se colocó en tubos de ensaye con tapa de rosca de $10 \mathrm{~mL}$. Se adicionó $0.1 \mathrm{~mL}$ de $\mathrm{NaOH}(10 \mathrm{~N})$. Posterior a la agitación mediante un vortex, se calentaron los tubos por $20 \mathrm{~min}$ a $90^{\circ} \mathrm{C}$ en un baño seco. Se necesitaron tres soluciones: (a) $\mathrm{Na}_{2} \mathrm{CO}_{3} 0.19$ $\mathrm{M}$ en $\mathrm{NaOH} 0.1 \mathrm{~N}$, (b) $\mathrm{CuSO}_{4}$ al $1 \%$ y (c) tartrato de sodio y potasio al $2 \%$. Se preparó una solución de trabajo ( $1 \mathrm{~mL}$ solución (b) + $1 \mathrm{~mL}$ de solución (c) + $48 \mathrm{~mL}$ de solución (a)) que fue posteriormente adicionada a cada tubo (5 mL). Se dejaron reposar los tubos por 30 min en la oscuridad. Posteriormente, se agregó $1 \mathrm{~mL}$ de reactivo de FolinCiocalteau, dejando reposar nuevamente en la oscuridad por $1 \mathrm{~h}$, para finalmente medir la absorbancia a $750 \mathrm{~nm}$ en un espectrofotómetro UV/VIS (Shimadzu, mod. UV-1601). La Figura 7 muestra un ejemplo de las curvas de calibración obtenidas.

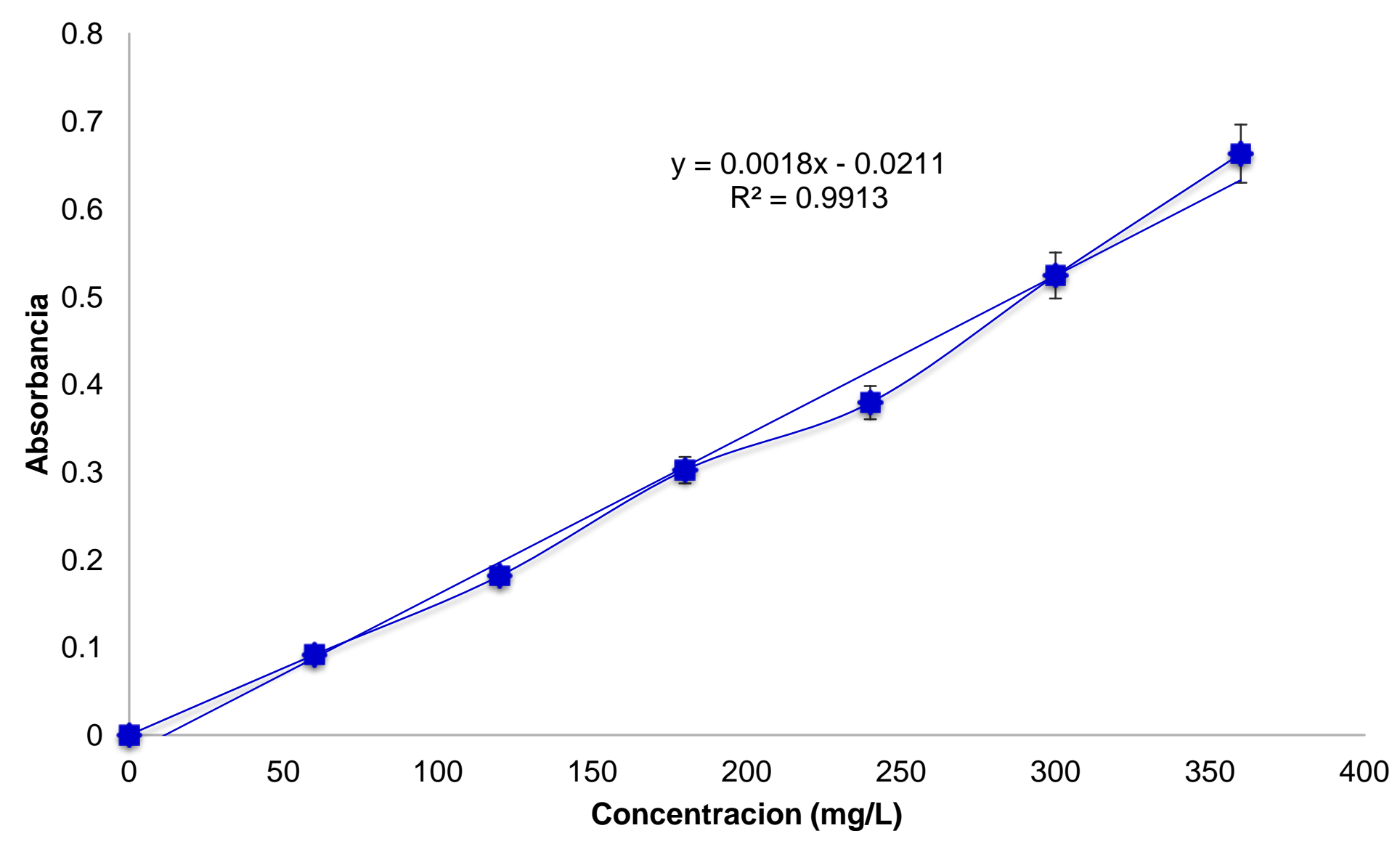

Figura 7. Curva de calibración para la cuantificación de proteína microbiana por el método de Lowry. 


\subsection{Variables de respuesta}

Para evaluar el efecto del BT a diferentes concentraciones iniciales sobre el proceso respiratorio nitrificante, se utilizaron variables de respuesta que proporcionaron información global del proceso: la eficiencia, los rendimientos y las velocidades específicas.

La eficiencia en el consumo de amonio y benzotriazol ( $\mathrm{E}_{\mathrm{NH} 4}, \%$; $\mathrm{E}_{\mathrm{BT}}$, \%) se definieron como la capacidad del consorcio nitrificante para consumir los compuestos (Ecuación 10).

Ecuación 10

$$
\text { Eficiencia }=\left(\frac{[\text { Sustrato inicial }]-[\text { Sustrato final }]}{[\text { Sustrato inicial }]}\right) *(100)
$$

El rendimiento de producción de nitrato $\left(\mathrm{Y}_{\mathrm{NO} 3}, \mathrm{~g} \mathrm{~N}-\mathrm{NO}_{3}{ }^{-} / \mathrm{g} \mathrm{N}-\mathrm{NH}_{4}{ }^{+}\right.$consumido) se definió como la cantidad de nitrato formado a partir del amonio (sustrato) utilizado (Ecuación 11). Se determinaron también los rendimientos de nitrito ( $\left.\mathrm{Y}_{\mathrm{NO} 2}\right)$ y biomasa formada $\left(\mathrm{Y}_{\mathrm{BM}}\right)$.

Ecuación $11 \quad$ Rendimiento $=\frac{m g \text { Producto formado }}{m g \text { Sustrado consumido }}$

Se determinaron las velocidades específicas de consumo de amonio (qNH4), consumo de BT (qBT) y producción de nitrato (qNO3); dividiendo las velocidades volumétricas determinadas a partir de las cinéticas establecidas entre la concentración de proteína microbiana.

Se estableció el balance de materia para nitrógeno (Ecuación 12)

Ecuación $12 \quad\left[\mathrm{~N}-\mathrm{NH}_{4}^{+}\right]_{\text {inicio }}=\left[\mathrm{N}-\mathrm{NH}_{4}^{+}\right]_{\text {final }}+\left[\mathrm{N}-\mathrm{NO}_{2}{ }^{-}\right]+\left[\mathrm{N}-\mathrm{NO}_{3}{ }^{-}\right]+[\mathrm{N}$-biomasa formada $]$ 


\section{A91}

\section{RESULTADOS Y DISCUSION}

\subsection{Nitrificación}

Como inóculo, se utilizó un lodo nitrificante anteriormente expuesto a amonio y una mezcla de: fenol, o-cresol, $m$ cresol, $p$-cresol y sulfuro en un reactor SBR. Bajo estas condiciones de alimentación, se comprobó que el lodo mantuvo una actividad nitrificante completa y estable (Suárez García, 2016). Sin embargo, era importante darle seguimiento nuevamente a la actividad nitrificante del lodo en el SBR alimentado solamente con amonio antes de proceder a la adición del BT.

Se procedió a evaluar la actividad respiratoria nitrificante y se obtuvieron datos cinéticos de referencia antes de comenzar la adición de benzotriazol al cultivo nitrificante.

En la Figura 8, se muestra el perfil de las concentraciones de los compuestos nitrogenados en el influente y efluente del SBR en la etapa previa a la adición de BT (ciclos 1 - 39). En este periodo de evaluación, la concentración de amonio alimentada al reactor se mantuvo en $148.1 \pm 6.2 \mathrm{mg} \mathrm{N}-\mathrm{NH}_{4}{ }^{+} / \mathrm{L}$. De acuerdo a los resultados, el amonio residual y la acumulación de nitrito en el efluente fueron despreciables y se obtuvo como producto mayoritario al nitrato.

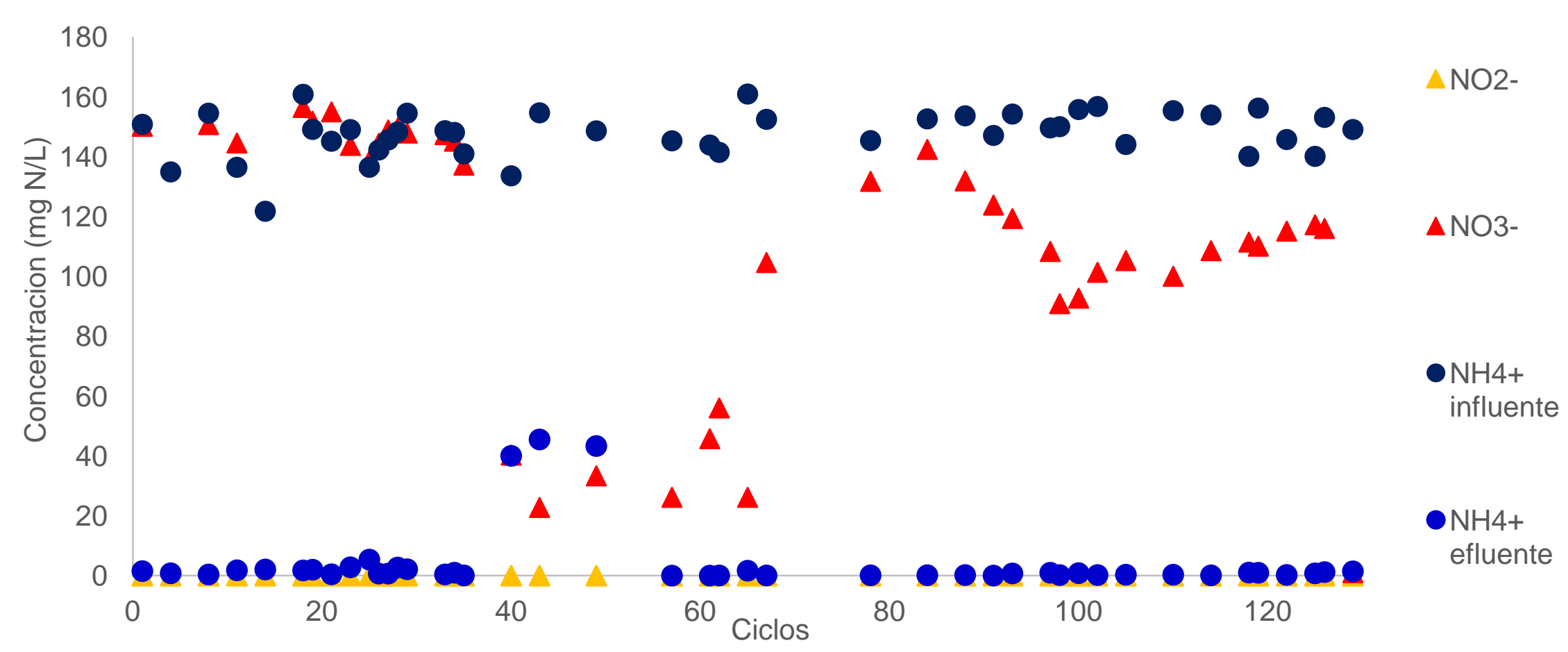

Figura 8. Perfil de concentraciones en compuestos nitrogenados en el influente e efluente del SBR sin y con adición de benzotriazol. 
Los resultados muestran que durante el primer periodo de operación del reactor sin adición de BT, se logró obtener una respiración nitrificante estable, obteniéndose una eficiencia de consumo de amonio del $99.6 \% \pm 0.3$ y un rendimiento en la formación de nitrato de $0.98 \pm 0.01 \mathrm{~g} \mathrm{~N}^{-N^{2}}{ }_{3} / \mathrm{g} \mathrm{N}-\mathrm{NH}_{4}{ }^{+}$consumido. El balance de $\mathrm{N}$ de la nitrificación en el SBR se presenta en la Tabla 3.

Tabla 3. Balance de N durante los ciclos de operación del SBR antes de adicionar BT (ciclos 1 - 39).

\begin{tabular}{c|cccc}
\hline Influente $(\mathbf{m g ~ N} / \mathbf{L})$ & \multicolumn{4}{|c}{ Efluente $(\mathbf{m g ~ N} / \mathbf{L})$} \\
\hline $\mathrm{N}^{-\mathrm{NH}_{4}}{ }^{+}$ & $\mathrm{N}^{-} \mathrm{NH}_{4}{ }^{+}$ & $\mathrm{N}-\mathrm{NO}_{2}{ }^{-}$ & $\mathrm{N}-\mathrm{NO}_{3}{ }^{-}$ & $\mathrm{N}-\mathrm{BM}$ \\
$148.1 \pm 9.1$ & $1.5 \pm 1.2$ & 0 & $147.4 \pm 5.3$ & $0.02 \pm 0.01$ \\
\hline
\end{tabular}

En la Figura 9a, se muestra un ejemplo del perfil cinético de consumo de amonio y producción de nitrito y nitrato en el ciclo 35, antes de adicionar el BT. Los resultados muestran la capacidad del lodo para oxidar el amonio a nitrito y nitrato mediante la nitrificación. La acumulación de nitrito en el cultivo fue transitoria y después de $23 \mathrm{~h}$ de reacción, la $E_{\mathrm{NH}_{4}+}$ fue de $99.8 \% \pm 0.1$ y el $\mathrm{Y}_{\mathrm{NO} \text { - }}$ de $0.98 \pm 0.01$; esto indicó que el nitrato fue el producto final del proceso respiratorio nitrificante.

Se midió la producción de biomasa a lo largo de los ciclos de operación obteniéndose un rendimiento de $0.01 \pm 0.01$ g N-biomasa producida/g N-NH${ }_{4}^{+}$consumido, indicando que el crecimiento celular fue bajo debido a un proceso respiratorio principalmente desasimilativo. 


\section{A91}
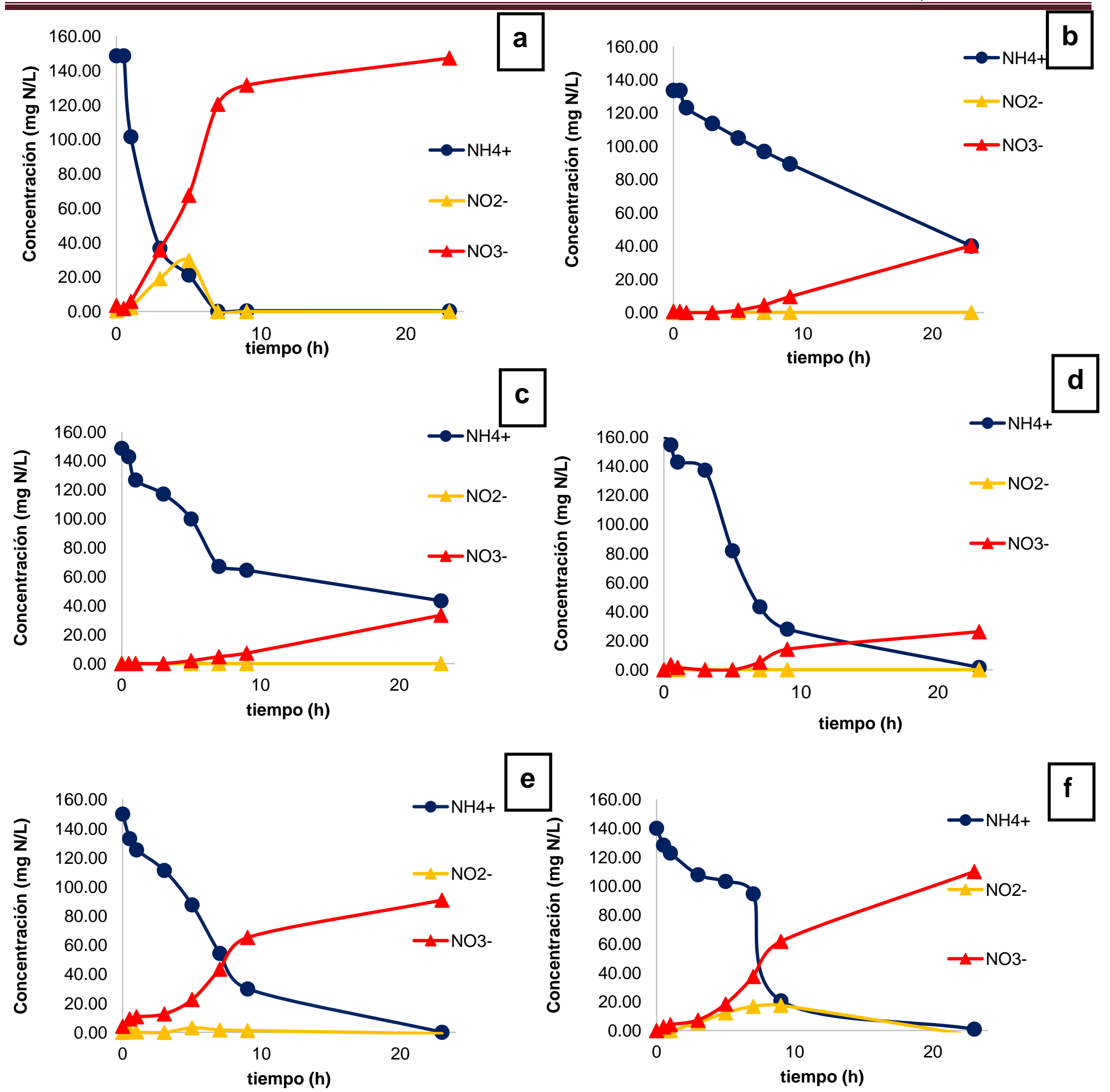

Figura 9. Perfil cinético del proceso nitrificante en el SBR: a) Ciclo 35 antes de agregar benzotriazol; b) Ciclo 40 después de agregar $5 \mathrm{mg} / \mathrm{L}$ de benzotriazol; c) Ciclo 48 con $5 \mathrm{mg} / \mathrm{L}$ de benzotriazol; d) Ciclo 67 con $5 \mathrm{mg} / \mathrm{L}$ de benzotriazol; e) Ciclo 100 con $5 \mathrm{mg} / \mathrm{L}$ de benzotriazol; f) Ciclo 120 con $5 \mathrm{mg} / \mathrm{L}$ de benzotriazol. 


\subsection{Efecto del benzotriazol sobre la nitrificación}

En la Figura 9b, c, d, e, f; se muestran los perfiles cinéticos posteriores a la adición de benzotriazol al SBR con una concentración de $5 \mathrm{mg} / \mathrm{L}$ correspondientes a los ciclos 40, 48, 67, 100 y 120, respectivamente.

En el primer ciclo de adición de BT (ciclo 40) (Figura 9b), se observó la acumulación de amonio en el efluente después de 23 h y una menor producción de nitrato respecto al ciclo 35 de referencia sin BT (Figura 9a). No se detectó nitrito en el reactor durante las $23 \mathrm{~h}$ de cultivo. En este primer ciclo de adición de BT al reactor, el proceso nitrificante tuvo una $\mathrm{E}_{\mathrm{NH}_{4}}$ del $70.0 \%$ y un $\mathrm{Y}_{\mathrm{NO} \text { - }}$ de 0.30 (Tabla 4). Ocho ciclos después de mantener el lodo expuesto a este compuesto, se obtuvieron resultados similares con amonio residual en el efluente, una baja formación de nitrato y sin acumulación de nitrito (Figura 9c). En el ciclo 48, la eficiencia se mantuvo prácticamente constante, pero el rendimiento en la formación de nitrato disminuyó nuevamente a un valor de 0.22 (Tabla 4). La disminución en la eficiencia respecto al valor de referencia obtenido en el periodo de evaluación sin BT (ciclos 1 - 39) indicó que la adición de BT provocó un efecto negativo en la oxidación de amonio. Además, la disminución en el valor de rendimiento de nitrato indicó que se llevó a cabo una nitrificación parcial, indicando un efecto negativo del compuesto orgánico sobre la producción de nitrato. Sin embargo, se pudo comprobar también que no hubo acumulación de nitrito, por lo tanto parte del amonio consumido no fue oxidado ni a nitrito ni a nitrato. El producto de oxidación de amonio pudiera ser hidroxilamina $\left(\mathrm{NH}_{2} \mathrm{OH}\right)$, que es un intermediario en la oxidación de amonio.

Tabla 4. Eficiencia y rendimiento durante el proceso respiratorio nitrificante.

\begin{tabular}{ccccc}
\hline $\begin{array}{c}\text { Benzotriazol } \\
(\mathbf{m g} / \mathbf{L})\end{array}$ & Ciclos & $\mathbf{E}_{\mathrm{NH}_{4}+(\%)}$ & $\mathbf{Y}_{\text {NO2- }}$ & $\mathbf{Y}_{\text {NO3- }}$ \\
\hline 0 & $1-39$ & $99.6 \pm 0.3$ & 0.00 & $0.98 \pm 0.01$ \\
\hline 5 & $1(40)$ & 70.0 & 0.00 & 0.30 \\
\hline 5 & $8(48)$ & 70.9 & 0.00 & 0.22 \\
\hline 5 & $27(67)$ & 98.9 & 0.00 & 0.16 \\
\hline 5 & $60(100)$ & 99.9 & 0.00 & 0.34 \\
\hline 5 & $80(120)$ & 99.3 & 0.00 & 0.79 \\
\hline
\end{tabular}


Como se puede observar en la Figura 9d, el proceso de amonio oxidación se mejoró en el ciclo 67 con el consumo total de amonio después de $23 \mathrm{~h}$, obteniéndose una eficiencia de $98.9 \%$. Sin embargo, el rendimiento de nitrato siguió disminuyendo (Tabla 4). Al paso de los ciclos de operación del SBR, se registró también una mejora en la formación de nitrato (Figuras 9e y 9f) con un aumento en el rendimiento (Tabla 4). En el ciclo 120, se determinó una eficiencia de $99.3 \% \pm 0.1$ y un rendimiento de 0.79 .

En la Tabla 5, se presenta el balance de nitrógeno correspondiente al periodo de evaluación del ciclo 80 al ciclo 130 (Figura 8). Se detectó un faltante de $35 \mathrm{mg} / \mathrm{L}$ de nitrógeno en el balance. Esto pudiera ser debido a la acumulación de hidroxilamina en el proceso de nitrificación, sin embargo más investigación es necesaria en este tema.

Tabla 5. Balance de N durante los ciclos 80-130 de operación del SBR con 5 mg/L BT.

\begin{tabular}{c|cccc}
\hline Influente $(\mathbf{m g ~ N} / \mathbf{L})$ & \multicolumn{4}{|c}{ Efluente (mg N/L) } \\
\hline $\mathrm{N}^{-\mathrm{NH}_{4}+}$ & $\mathrm{N}^{+}-\mathrm{NH}_{4}^{+}$ & $\mathrm{N}^{+} \mathrm{NO}_{2}^{-}$ & $\mathrm{N}-\mathrm{NO}_{3}^{-}$ & $\mathrm{N}-\mathrm{BM}$ \\
$149.2 \pm 6.3$ & $0.6 \pm 0.4$ & 0 & $112.2 \pm 13.5$ & $0.02 \pm 0.01$ \\
\hline
\end{tabular}

Así mismo, la adición de benzotriazol en el ciclo 40 provocó una disminución del $58 \%$ en la $\mathrm{q}_{\mathrm{NH} 4+} \mathrm{y} 62 \%$ en la $\mathrm{q}_{\mathrm{NO}-}$ (Tabla 6), con respecto a los valores obtenidos en el reactor durante la etapa previa a la adición del BT. Esto nos indica que hay un efecto inhibitorio del BT sobre la nitrificación afectando al proceso amonio oxidante como al proceso nitrito oxidante. Estos resultados coinciden con lo reportado anteriormente por Salas Cortes en 2014, donde en un reactor SBR alimentado con $10 \mathrm{mg} / \mathrm{L}$ de $m$-cresol, se observó una disminución del $66 \%$ en la $\mathrm{q}_{\mathrm{NH} 4+}$ y del $90 \%$ en la q $_{\mathrm{NO}^{-}}$- respecto a los valores obtenidos en el mismo reactor sin adición de $m$-cresol. Por otro lado, no se detectó acumulación de nitrito en el reactor, lo cual indicó que en el primer ciclo de adición de BT, la disminución (62\%) en la velocidad específica de producción de nitrato fue principalmente causada por la disminución en la velocidad específica de oxidación de amonio a nitrito (58\%). Algunos autores han propuesto que el efecto inhibitorio de la materia orgánica sobre la nitrificación puede estar relacionado con una inhibición sobre la enzima AMO. Sin embargo, se ha reportado que esta enzima es capaz de oxidar una amplia variedad de compuestos orgánicos (Keener y Arp, 1993, 1994; McCarty, 1999; Duddleston, 2002). 
Después de 8 ciclos de mantener el lodo expuesto al benzotriazol, la $\mathrm{q}_{\mathrm{NH} 4+}$ aumentó $61 \%$ con respecto al primer ciclo de adición de benzotriazol, es decir, la inhibición causada por este compuesto fue disminuyendo al paso de los ciclos de operación del SBR, tal y como lo reportó Salas Cortes (2014) en un reactor SBR nitrificante alimentado con mezclas de cresoles donde al paso de los ciclos de operación, el efecto inhibitorio sobre la nitrificación disminuyó significativamente. Sin embargo, en el presente estudio, la qNO3- siguió disminuyendo 8 ciclos después en un $46 \%$, evidenciando un efecto inhibitorio mayor sobre la nitrito oxidación que sobre la amonio oxidación. Al mantener el lodo expuesto a $5 \mathrm{mg} / \mathrm{L}$ de BT durante 8 ciclos, la velocidad de oxidación de amonio aumentó, pero no se detectó nitrito como intermediario y la velocidad de formación de nitrato siguió disminuyendo, lo cual podría sugerir un efecto inhibitorio en la oxidación de hidroxilamina a nitrito más que en la oxidación de nitrito a nitrato.

Al paso de los ciclos, la inhibición sobre la velocidad específica de consumo de amonio ( $\mathbf{q}_{\mathrm{NH} 4_{+}}$) disminuyó;

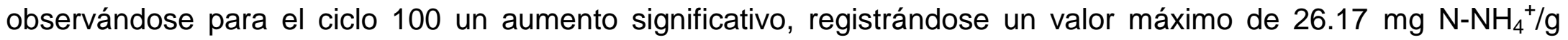
SSV.h. Aunque fueron necesarios una mayor cantidad de ciclos de operación para que la $\mathrm{qNO}_{3}{ }^{-}$se recuperase, se obtuvo un valor de $9.72 \mathrm{mg} \mathrm{N}-\mathrm{NO}_{3}{ }^{-} / \mathrm{g} \mathrm{SSV} \cdot \mathrm{h}$ que es cercano al obtenido antes de adicionar el BT. Estos resultados muestran que el uso del SBR puede ser una buena alternativa para favorecer la disminución del efecto inhibitorio de los Compuestos Orgánicos Emergentes (EOCs) sobre el proceso nitrificante a través de los ciclos de operación.

Tabla 6. Velocidades específicas de la nitrificación con 0 de BT y 5 mg/L durante el proceso respiratorio nitrificante.

\begin{tabular}{cccc}
\hline $\begin{array}{c}\text { Benzotriazol } \\
(\mathbf{m g} / \mathbf{L})\end{array}$ & Ciclos & $\begin{array}{c}\mathbf{q}_{\mathrm{NH}_{4}}{ }^{+} \\
(\mathbf{m g ~ N} / \mathbf{g ~ S S V ~ h})\end{array}$ & $\begin{array}{c}\mathbf{q}_{\mathrm{NO}_{3}}{ }^{-} \\
(\mathbf{m g ~ N} \mathbf{g ~ S S V ~ h})\end{array}$ \\
\hline 0 & $1-39$ & $19.92 \pm 0.03$ & $10.53 \pm 0.02$ \\
\hline 5 & $1(40)$ & 8.32 & 4.02 \\
\hline 5 & $8(48)$ & 13.44 & 2.17 \\
\hline 5 & $27(67)$ & 23.19 & 1.45 \\
\hline 5 & $60(100)$ & 26.17 & 8.78 \\
\hline 5 & $80(120)$ & 11.20 & 9.72 \\
\hline
\end{tabular}




\subsection{Consumo de benzotriazol}

Con respecto al consumo de benzotriazol, la Figura 10 muestra el perfil cinético de la oxidación del benzotriazol por el consorcio nitrificante. En el ciclo 40 (ciclo 1), no hubo consumo del benzotriazol durante el tiempo de reacción, indicando que este compuesto fue recalcitrante; sin embargo, 8 ciclos después, el consumo de BT fue del 100\% en tan solo 5 horas, mejorando al paso de los ciclos obteniéndose una velocidad de consumo de benzotriazol $\left(\mathrm{q}_{\mathrm{Btri}}\right) \mathrm{de}$ $5.41 \mathrm{mg} \mathrm{C}-\mathrm{BT} / \mathrm{g}$ SSV·h, mostrando así, una adaptación metabólica del lodo a este compuesto. Estudios anteriores han mostrado que la bacteria amonio oxidante Nitrosomonas europaea fue capaz de oxidar una amplia variedad de hidrocarburos aromáticos y no aromáticos, donde se propone que la enzima AMO estuvo involucrada (Hyman y col., 1985; Rasche y col., 1990; Chang y col., 2002; Yi y Harper, 2007; Rho y col., 2009).

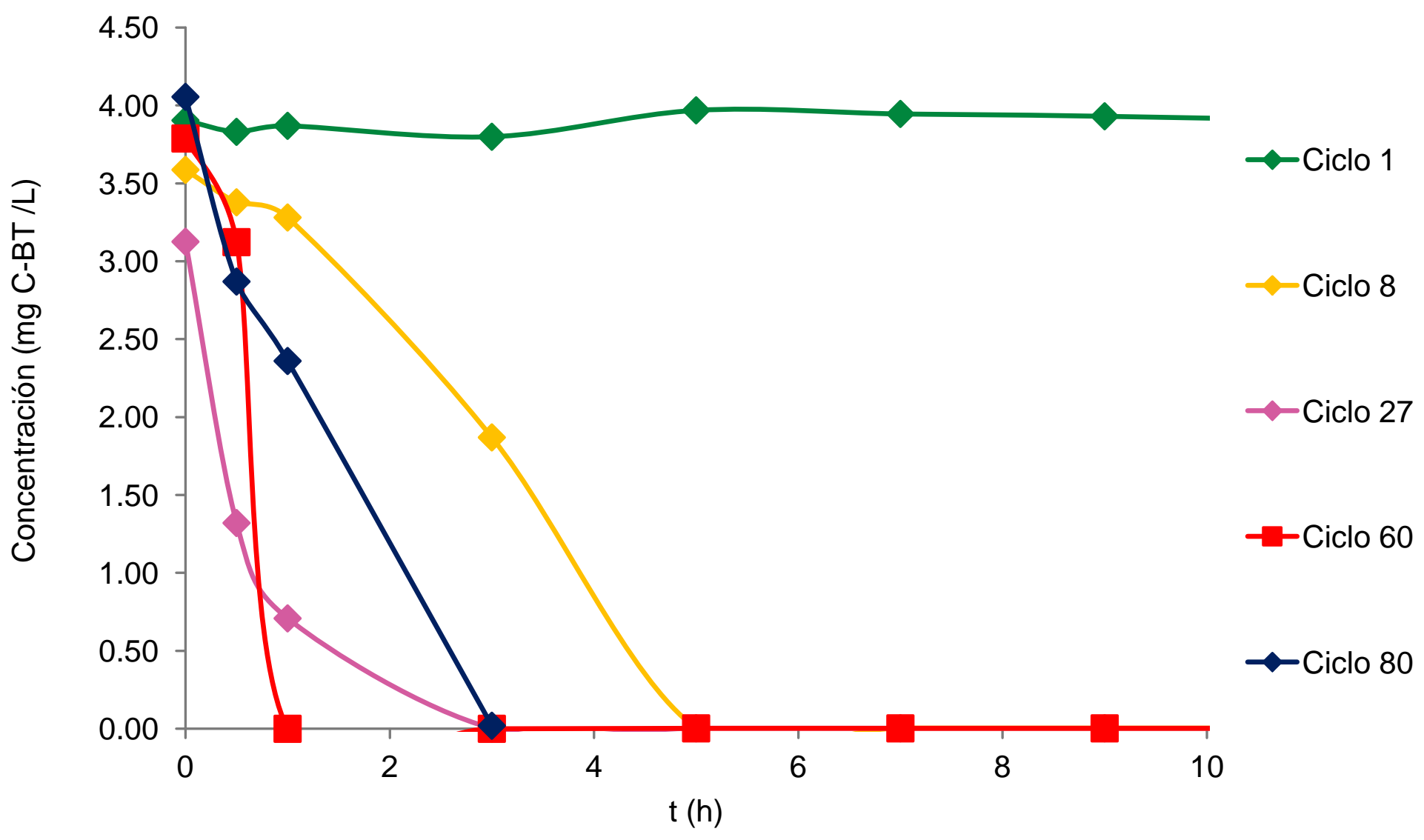

Figura 10. Perfil cinético del consumo de benzotriazol durante el proceso respiratorio nitrificante. 
Cabe destacar que al aumentar la velocidad de consumo de BT, también aumentaron las velocidades de los procesos nitrificantes (Tabla 7). Esto demuestra que la disminución del efecto inhibitorio de este compuesto orgánico a través de los ciclos de operación del SBR está relacionada con una mayor capacidad metabólica del consorcio en consumir el compuesto recalcitrante.

Tabla 7. Velocidades específicas del consumo del Benzotriazol con una concentración de 5mg/L.

\begin{tabular}{ccc}
\hline $\begin{array}{c}\text { Benzotriazol } \\
(\mathbf{m g} / \mathbf{L})\end{array}$ & Ciclos & $\begin{array}{c}\mathbf{q}_{\mathrm{BT}} \\
(\mathrm{mg} \mathrm{C}-\mathrm{BT} / \mathbf{g ~ S S V ~ h})\end{array}$ \\
\hline 0 & $1-39$ & - \\
\hline 5 & $1(40)$ & 0.004 \\
\hline 5 & $8(48)$ & 0.915 \\
\hline 5 & $27(67)$ & 3.060 \\
\hline 5 & $60(100)$ & 4.795 \\
\hline 5 & $80(120)$ & 1.614 \\
\hline
\end{tabular}

Durante la determinación del BT mediante la técnica de HPLC (high performance liquid chromatography) se detectó la presencia de un intermediario. En la Figura 11, se muestran los valores de área al final de cada ciclo. Se observa que los valores van en aumento al paso de los ciclos, indicando una mayor acumulación del intermediario del BT en el efluente.

En el trabajo realizado por Huntscha y col. en 2014, se investigaron los posibles mecanismos de degradación biológica aerobia de los benzotriazoles utilizando lodos activados. Los autores realizaron la identificación de productos de transformación transitoria y persistentes en experimentos discontinuos utilizando cromatografía líquidaespectrometría de masas de alta resolución (LC-HR-MS / MS) para su determinación. Los principales productos de transformación se identificaron como 4- y 5-hidroxi-1H-benzotriazol. Estos resultados nos dan un indicio del posible intermediario; sin embargo, aún falta hacer pruebas para confirmar dicha información. 
450000

400000

350000

300000

$\frac{\mathbb{d}}{\frac{1}{4}}$

200000

150000

100000

50000

0

Ciclo1

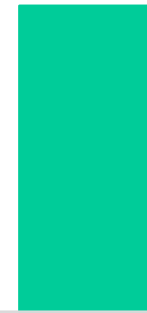

Ciclo8

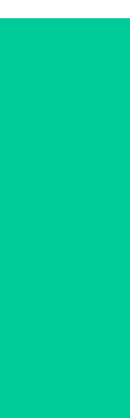

Ciclo 27

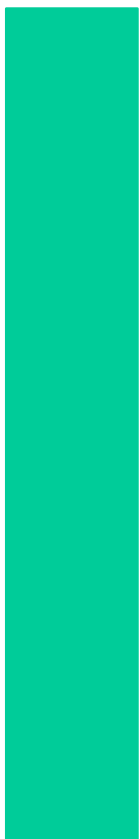

Ciclo 60

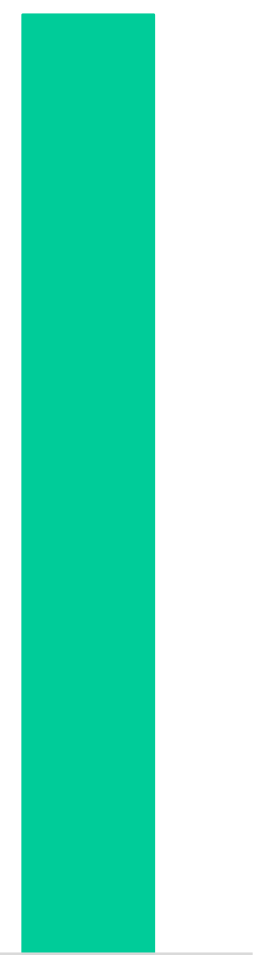

Ciclo 80

Figura 11. Grafica de valores de área del intermediario detectado por HPLC al final de cada ciclo. 


\section{CONCLUSIONES}

- Se evidenció el efecto inhibitorio del benzotriazol sobre la nitrificación registrándose una disminución de la $\mathrm{q}_{\mathrm{NH} 4+}$ en un $58 \%$ y sobre la $\mathrm{q}_{\mathrm{NO}}$ - en un $62 \%$ en el primer ciclo.

- Durante el paso de los ciclos de operación del SBR, se observó una disminución del efecto inhibitorio del BT, obteniéndose un aumento significativo en la $\mathrm{q}_{\mathrm{NH} 4_{+}}$y la q $_{\mathrm{NO}}$ - después de 80 ciclos de exposición del lodo nitrificante al BT.

- Después de 80 ciclos de operación, se obtuvo un proceso nitrificante estable en el reactor de lotes secuenciados con una eficiencia de consumo de amonio del 99.3\% y un rendimiento de formación de nitrato de 0.79 en presencia de $5 \mathrm{mg} / \mathrm{L}$ de benzotriazol.

- El benzotriazol permaneció recalcitrante durante $23 \mathrm{~h}$ del primer ciclo de adición, sin embargo, después de 8 ciclos de operación del SBR el lodo nitrificante fue capaz de consumirlo con una eficiencia del $100 \%$ en tan solo 5 horas.

- El aumento en la $\mathrm{q}_{\mathrm{Btri}}$ a través de los ciclos muestra que el lodo nitrificante adquirió y aumentó su capacidad metabólica para oxidar el benzotriazol. 


\section{BIBLIOGRAFIA}

- Asimakopoulos, A. G., Wang, L., Thomaidis, N. S. and Kannan, K. (2013). Benzotriazoles and benzothiazoles in human urine from several countries: a perspective on occurrence, biotransformation, and human exposure. Environ. Int. 59: 274-281.

- Bernet N. y Spérandio M. (2009). Principles of nitrifying processes. Environmental technologies to treat nitrogen pollution. $1^{\text {st }}$ edition. Editorial: IWA Publishing. London. 23-39.

- Bock E., Koops H.P., Harms H. and Ahler B. (1991). The biochemistry of nitrifying organisms. Variations in autotrophic life. Editorial: Academic Press, San Diego. 171-200.

- Cornell, J. S., Pillard, D. A., and Hernandez, M. T. (2000). Comparative measures of the toxicity of component chemicals in aircraft deicing fluid. Environmental Tox. 19(6): 1465-1472.

- Eiroa M., Kennes C. y Veiga M.C. (2004). Formaldehyde biodegradation and its inhibitory effect on nitrification. Journal of Chemical Technology and Biotechnology. 79, 499-504.

- Fawell, J., and Ong, C. N. (2012). Emerging contaminants and the implications for drinking water. International Journal of Water Resources Development. 28(2): 247-263.

- Giger, W., Schaffner, C., and Kohler, H. P. E. (2006). Benzotriazole and tolyltriazole as aquatic contaminants. 1. Input and occurrence in rivers and lakes. Environmental science \& technology. 40(23): 7186-7192.

- Harris, C. A., Routledge, E. J., Schaffner, C., Brian, J. V., Giger, W., and Sumpter, J. P. (2007). Benzotriazole is antiestrogenic in vitro but not in vivo. Environmental Toxicology and Chemistry. 26(11): 2367-2372.

- Hart, D. S., Davis, L. C., Erickson, L. E., and Callender, T. M. (2004). Sorption and partitioning parameters of benzotriazole compounds. Microchemical Journal. 77(1): 9-17.

- Hartwell, S. I., Jordahl, D. M., Evans, J. E., and May, E. B. (1995). Toxicity of aircraft de-icer and anti-icer solutions to aquatic organisms. Environmental toxicology and chemistry. 14(8): 1375-1386.

- Hem, L. J., Weideborg, M., and Schram, E. (2000). Degradation and toxicity of additives to aircraft de-icing fluids; the effect of discharge of such fluids to municipal wastewater treatment plants. Proceedings of the Water Environment Federation. 2000(5): 419-433.

- Hollender, J., Singer, H., and McArdell, C. S. (2008). Polar organic micropollutants in the water cycle. In Dangerous pollutants (Xenobiotics) in urban water cycle. Springer. Netherlands. 103-116. 
- Huntscha, Sebastian, y co. (2014). "Biotransformation of benzotriazoles: insights from transformation product identification and compound-specific isotope analysis." Environmental science \& technology 48.8:4435-4443.

- Janna, H., Scrimshaw, M. D., Williams, R. J., Churchley, J., and Sumpter, J. P. (2011). From dishwasher to tap? Xenobiotic substances benzotriazole and tolyltriazole in the environment. Environmental science \& technology. 45(9): 3858-3864.

- Jover, E., Matamoros, V., and Bayona, J. M. (2009). Characterization of benzothiazoles, benzotriazoles and benzosulfonamides in aqueous matrixes by solid-phase extraction followed by comprehensive twodimensional gas chromatography coupled to time-of-flight mass spectrometry. Journal of Chromatography A. 1216(18): 4013-4019.

- Kadar, E., Dashfield, S., and Hutchinson, T. H. (2010). Developmental toxicity of benzotriazole in the protochordate Ciona intestinalis (Chordata, Ascidiae). Analytical and bioanalytical chemistry. 396(2): 641-647.

- Kim, J. W., Ramaswamy, B. R., Chang, K. H., Isobe, T., and Tanabe, S. (2011). Multiresidue analytical method for the determination of antimicrobials, preservatives, benzotriazole UV stabilizers, flame retardants and plasticizers in fish using ultra high performance liquid chromatography coupled with tandem mass spectrometry. Journal of Chromatography A. 1218(22): 3511-3520.

- Kiss, A., and Fries, E. (2009). Occurrence of benzotriazoles in the rivers Main, Hengstbach, and Hegbach (Germany). Environmental Science and Pollution Research. 16(6): 702-710.

- Kiss, A., and Fries, E. (2012). Seasonal source influence on river mass flows of benzotriazoles. Journal of Environmental Monitoring. 14(2): 697-703.

- Kowalchuck G. y Stephen J.R. (2001). Ammonia-oxidizing bacteria: A model for molecular microbial ecology. Annual Review of.Microbiology. 55: 485-529.

- Liu, Y. S., Ying, G. G., Shareef, A., and Kookana, R. S. (2011). Photolysis of benzotriazole and formation of its polymerized photoproducts in aqueous solutions under UV irradiation. Environmental chemistry. 8(2): 174181.

- Loos, R., Locoro, G., Comero, S., Contini, S., Schwesig, D., Werres, F. and Bolchi, M. (2010). Pan-European survey on the occurrence of selected polar organic persistent pollutants in ground water. Water Research. 44(14): 4115-4126 
- Malhas, R. N., Al-Awadi, N. A., and El-Dusouqui, O. M. (2007). Kinetics and mechanism of gas-phase pyrolysis of $\mathrm{N}$-aryl-3-oxobutanamide ketoanilides, their 2-arylhydrazono derivatives, and related compounds. International Journal of Chemical Kinetics. 39(2): 82-91.

- Martínez-Hernández S., Texier A-C., Cuervo-López F.M. y Gómez J. (2011). 2- Chlorophenol consumption and its effect on the nitrifying sludge. Journal of Hazardous Materials. 185: 1592-1595.

- Matamoros, V., Jover, E., and Bayona, J. M. (2010). Occurrence and fate of benzothiazoles and benzotriazoles in constructed wetlands. Water Science \& Technology. 61(1).

- McNeill, K. S., and Cancilla, D. A. (2009). Detection of triazole deicing additives in soil samples from airports with low, mid, and large volume aircraft deicing activities. Bulletin of environmental contamination and toxicology. 82(3): 265-269.

- Nevalainen I., Kostyal E., Nurmiaho-Lassila E-L., Puhakka J. y Salkinoja-Salonen M. (1993). Deschlorination of 2,4,6-trichlorophenol by a nitrifying biofilm. Water Research. 27(5): 757-767.

- Prosser J.I. (1989). Autotrophic nitrification in bacteria. Advances in microbial physiology. 30: 125-181.

- Quintana, J. B., Weiss, S., and Reemtsma, T. (2005). Pathways and metabolites of microbial degradation of selected acidic pharmaceutical and their occurrence in municipal wastewater treated by a membrane bioreactor. Water Research. 39(12): 2654-2664.

- Reemtsma, T., Weiss, S., Mueller, J., Petrovic, M., González, S., Barcelo, D., and Knepper, T. P. (2006). Polar pollutants entry into the water cycle by municipal wastewater: a European perspective. Environmental Science \& Technology. 40(17): 5451-5458.

- Schweighofer P., Nowak O., Svardal K. y Kroiss H. (1996). Steps towards the upgrading of a municipal WWTP affected by nitrification inhibiting compounds-A case study. Water Science and Technology. 33(12), 39-46.

- Silva C.D., Cuervo-López F.M., Gómez J. y Texier A-C. (2011). Nitrite effect on ammonium and nitrite oxidizing processes in a nitrifying sludge. World Journal of Microbiology and Biotechnology. 27, 1241-1245. DOI 10.1007/s11274-010- 0573-6.

- Silva, C.D., Gómez, J., Houbron, E., Cuervo-López, F.M., Texier, A.C., (2009). p-Cresol biotransformation by a nitrifying consortium. Chemosphere. 75(10): 1387-1391. 
- Silva C.D., Beristain-Montiel L., Cuervo-López F.M., Texier A.-C. (2014). p-Cresol mineralization and bacterial population dynamics in a nitrifying sequential batch reactor. Journal of Environmental Sciences. 26:18851893.

- Smith A.J. y Hoare D.S. (1968). Acetate assimilation by Nitrobacter agilis in relation to its "Obligate Autotrophy". . Journal of Bacteriology. 95(3), 844-855.

- Steinmüller W. y Bock E. (1977). Enzymatic studies of autotrophically, mixotrophically and heterotrophically grown of Nitrobacter agilis with special reference to nitrite oxidasa. Archives of Microbiology. 115: 51-54.

- Voutsa, D., Hartmann, P., Schaffner, C., and Giger, W. (2006). Benzotriazoles, alkylphenols and bisphenol A in municipal wastewaters and in the Glatt River, Switzerland. Environmental Science and Pollution Research. 13(5): 333-341.

- Ward M. H., de Kok T.M., Levallois P., Brender J., Gulis G., Nolan B. T. y Van Derslice, J. (2005). Workgroup report: drinking-water nitrate and health-recent findings and research needs. Environmental Health Perspectives. 113(11): 1607-1614.

- Watson S.W., Bock E., Koops H.P. y Hooper A. (1989). Bergey's Manual of Systematic Bacteriology. Volumen 3. Editorial: The Williams and Wilkins. Baltimore. 1808-1834.

- Weiss, S., Jakobs, J., and Reemtsma, T. (2006). Discharge of three benzotriazole corrosion inhibitors with municipal wastewater and improvements by membrane bioreactor treatment and ozonation. Environmental science \& technology. 40(23): 7193-7199.

- Wu, X., Chou, N., Lupher, D., \& Davis, L. C. (1998). Benzotriazoles: toxicity and degradation. In Conference on Hazardous Waste Research, Kansas City, MO.

- Zhang, Z., Ren, N., Li, Y. F., Kunisue, T., Gao, D., \& Kannan, K. (2011). Determination of benzotriazole and benzophenone UV filters in sediment and sewage sludge. Environmental science \& technology. 45(9): 39093916.

- Zwiener, C., and Frimmel, F. H. (2004). LC-MS analysis in the aquatic environment and in water treatment technology-a critical review. Analytical and bioanalytical chemistry. 378(4). 862-874. 


\section{ACTA DE IDÓNEA COMUNICACIÓN DE RESULTADOS}

EFECTO DEL BENZOTRIAZOL SOBRE LA NITRIFICACION EN DN REACTOR DE LOTE SECUENCIADO [SBR].

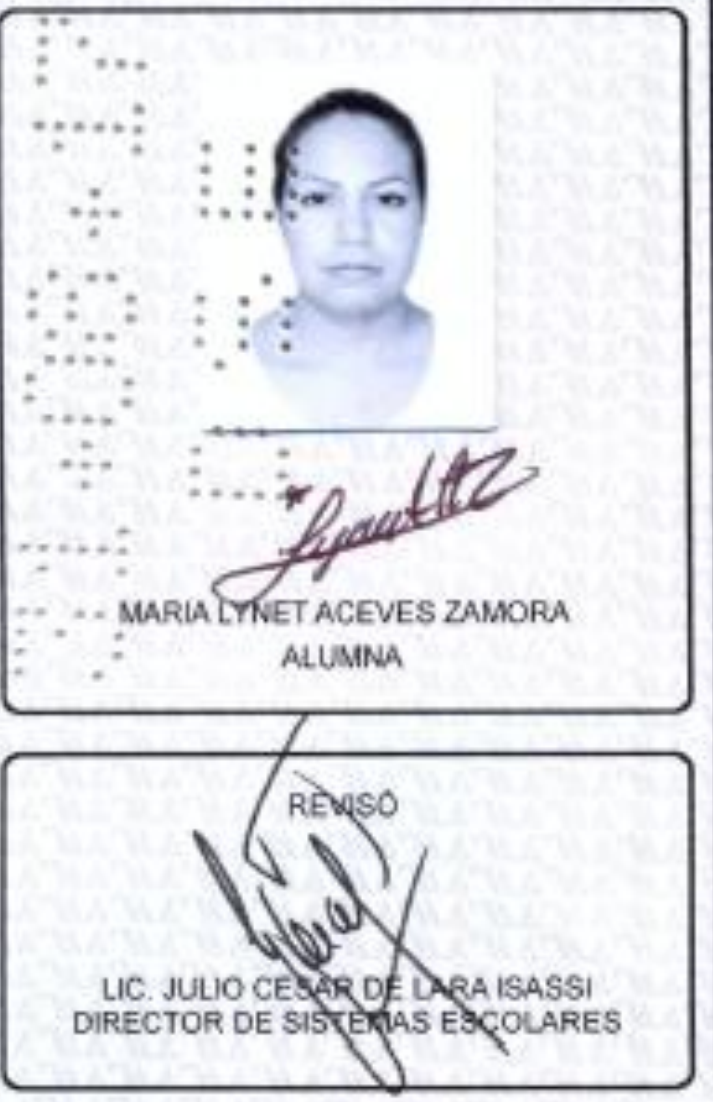

DIRECTORA DE LA DIVISIÓN DE CBS

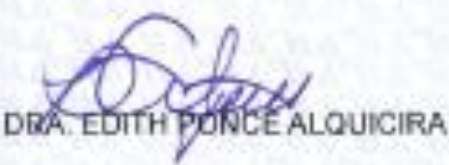

En la ciudad de México, se presentaron a las 11:00 horas del dia 28 del mes de agosto del año 2017 en la Unidad Iztapalapa de la Universidad Autonoma Metropolftana, los suscritos miembros del furado:

DRA. ANINE CLAIRE TEXIBR

DR. DIEGO IVAN BEJARANO ORTIZ

siendo la primera asesora de la aluma $y$ lector el sequndo, de la Idonea Comunicación de Resultados, se reunieron a evaluar la presentacion cuya denominación aparece al margen, para la obtención del diploma de:

ESPECIALIZACION EN BIOTECNOLOGIA

DE: MARTA TYNET ACEVES 2AMORA

$y$ de acuerdo con $\theta 1$ articulo 79 fraceión II del Reglamento de Estudios Superiores de la Universidad Autonoma Metropolitana, los miembros del jurado resolvieron:

\section{APROBAR}

Acto continuo, se coaunico a la interesada el resultado de la evaluación $y$, en caso aprobatorlo, le fue tomada la protesta. 